\title{
ECONOMIC IMPACT OF THE ENCROACHMENT OF THE AGRICULTURAL LAND IN EGYPT
}

\author{
SALAH ALSAYED ELWAN
}

Agricultural Economics Research Institute ARC, Ministry of Agriculture

(Manuscript received 14 February 2017)

\begin{abstract}
$\mathrm{T}$ he farmland encroachment caused great losses to the Egyption Agriculture, The area that has been infringed reached about 102059 Feddans during the period (19832014), The loss in total revenue for Wheat, Cotton and Rice reached about L.E 581, 541, 562 millions by price level in 2013. Furthermore, The loss of the infringed area during the period (Jan. 2011 - Jan 2014) to the same crops reached about L.E 345, 321, 334 millions respectively. The Economic loss of the total infringed area for the Agriculture Rotation Cotton and Clover amounted to about L.E 2353 represents about $0.83 \%$ from total Agricultural product in 2013 and $15.07 \%$ from the net Agricultural trade balance in the same year. In addition to this the equivalent loss in both Cotton and Rice exports amounted to about L.E 862, 896 millions moderat about $\$ 115,120$ million Dollars by pricing level in 2013 which represent about 4.36\%, 4.53\% from the total Agricultural exports value, Moreover, The equivalent loss in Wheat and Faba bean imports amounted to about L.E 926, 743 millions moderat about $\$ 124,99$ million dollars in 2013. The social loss has been measured by the unemployment as a result to the labor force due to the total infringed area which mounted to about 13.87 million day/ work for the Agricultural rotation of Cotton and clover which represents about L.E 832 as a farm income, but for the alternative rotation Rice and sugar beet, the loss amomnted to about 13.46 million day/work which represents about L.E 808 million as a farm income. The research reached some recommendations that may contribute to solve this problem, New legislation and monthly accurate reports should be prepared.
\end{abstract}




\section{الأثز الاقتصادي للتعديات على الأراضي الزراعية في مصر

$$
\text { صلاح السيد علوان }
$$

معهز بحوث الاقتصاد الزراعي - مركز البحوث الزراعية - دقى - جيزة

انتشرت ظاهرة التعدي على الأر اضي الزراعية بالتبوير و البناء خلال

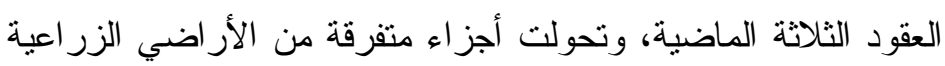

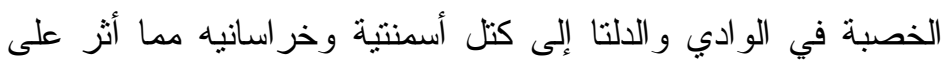

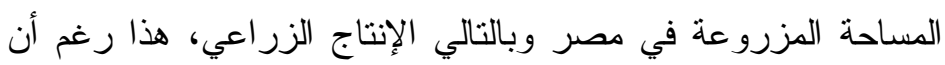

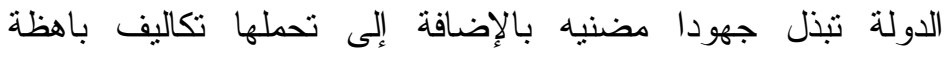

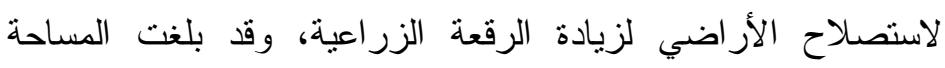

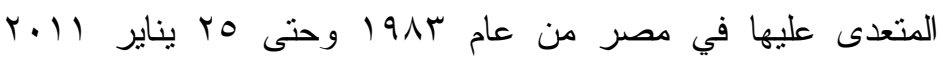

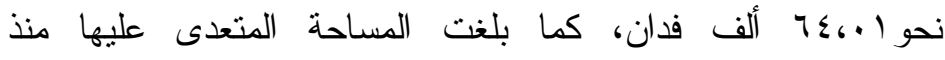

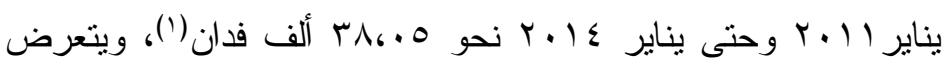

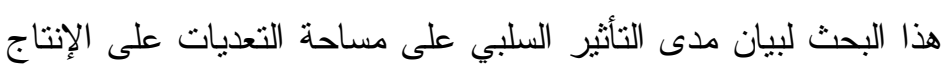
الزراعي والدورات الزراعية وكذلك الأثر الاجتماعي، وتجدر الإنشارة

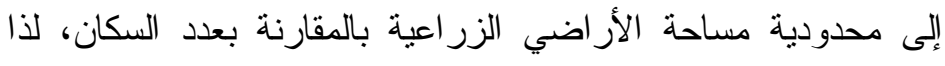

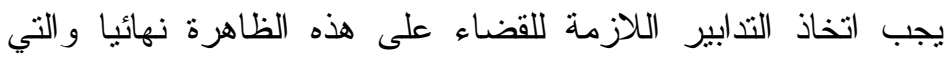

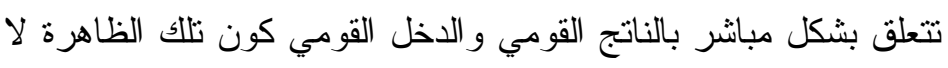

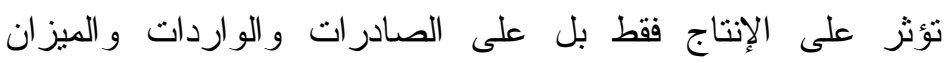

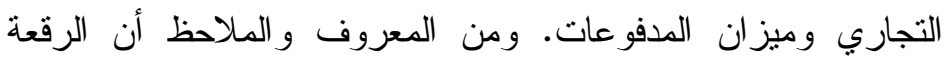

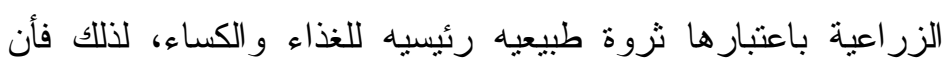

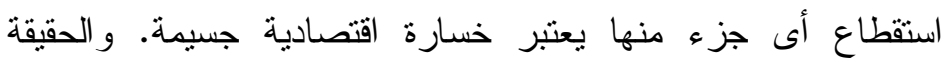

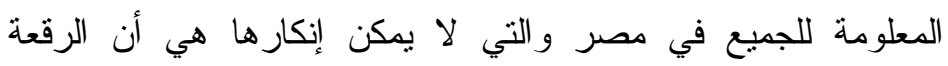

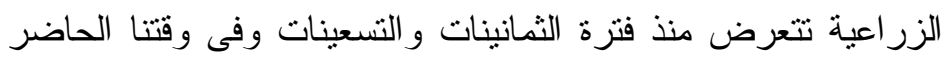

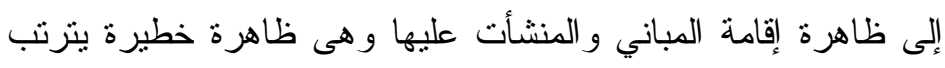

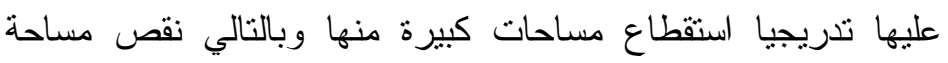

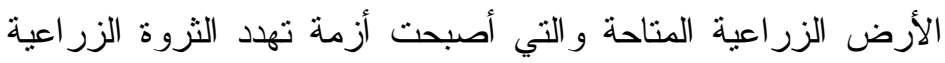




\section{مشكلة البحث}

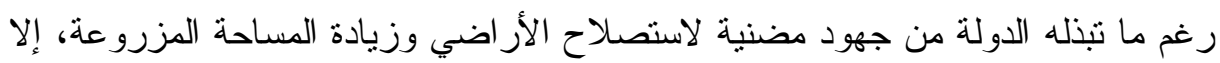

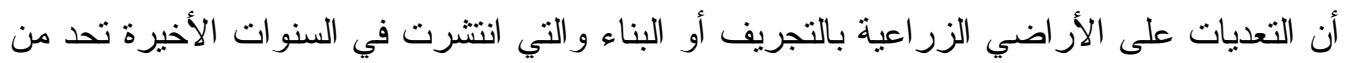

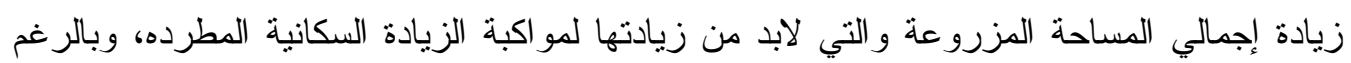

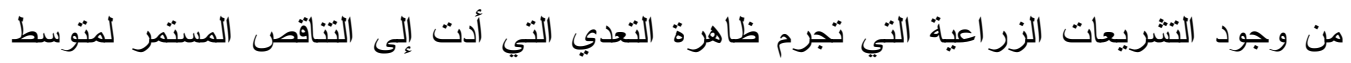

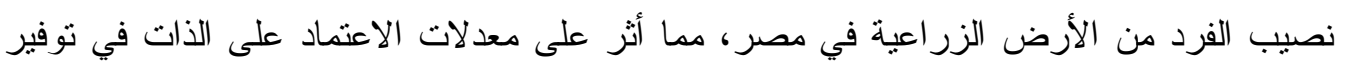
السلع الغذائية نتيجة التأثير على الإنتاج الزر اعي من الحاصلات التصديرية أو الاستير ادية مما يؤثر بشكل مباشر على تحقيق الأمن الغذائي المصري.

\section{هاف البحث}

يستهدف البحث تقييم أثز التعدي على الأر اضي الزر اعية على أهم المتغيرات الاقتصادية في القطاع

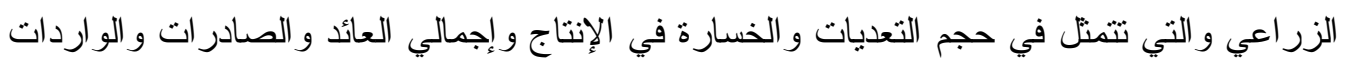

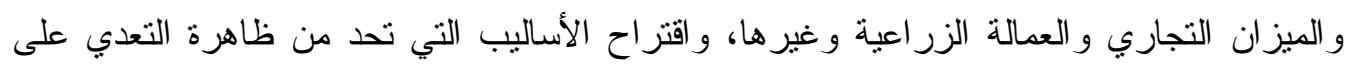

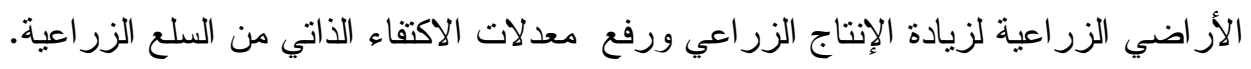

\section{الطريقة البحثية ومصادر البيانات}

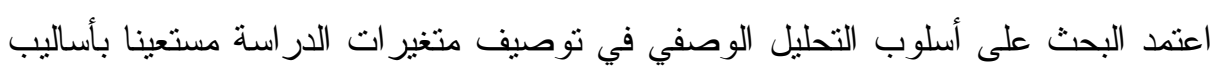

العرض الجدولي و التحليل الكمي متمنل في الأهمية النسبية و المنوسطات الحسابية.

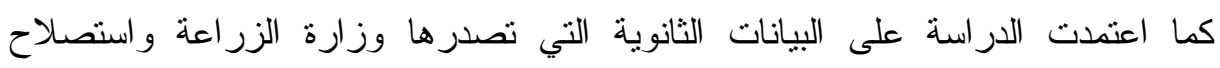

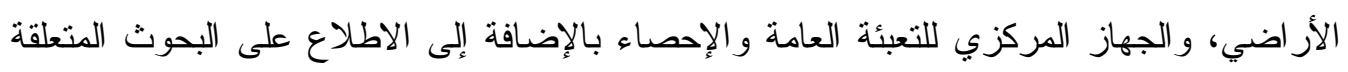

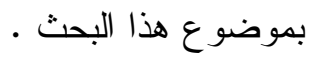

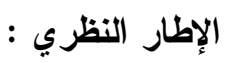

قبل البدء في استعر اض نتائج الدراسة سيتم التعرف على بعض المفاهيم الني نم الاستعانة

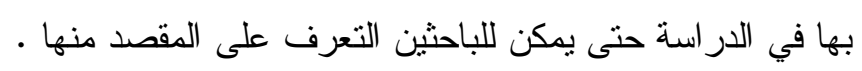

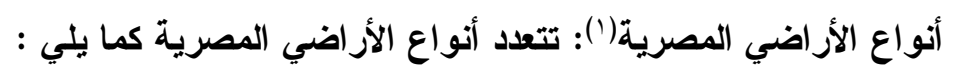

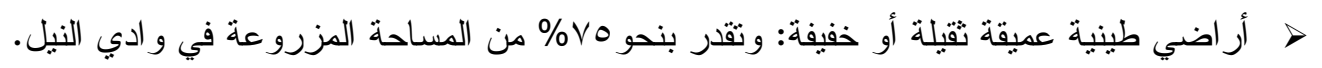

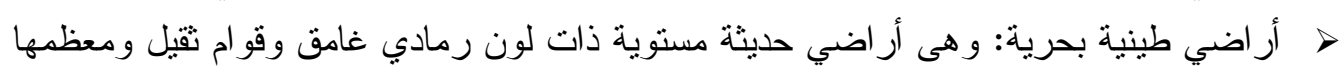

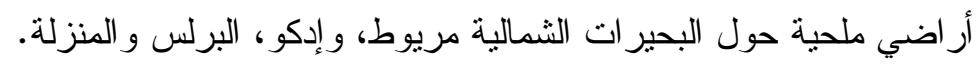

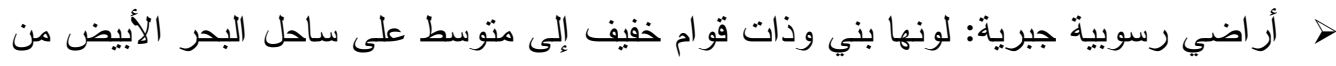
الإسكندرية لمطروح وداخل محافظة الفيوم.

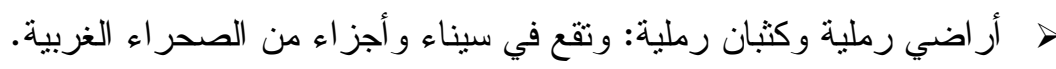

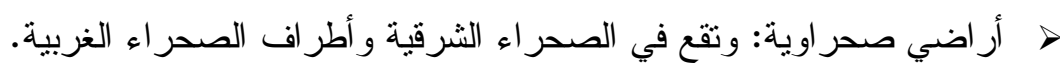


التصنيف الفيزيقي للأراضي الزراعية('):

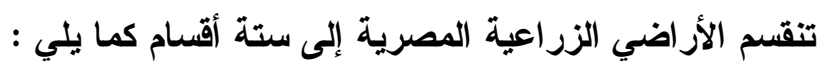

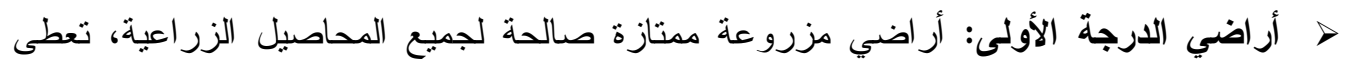

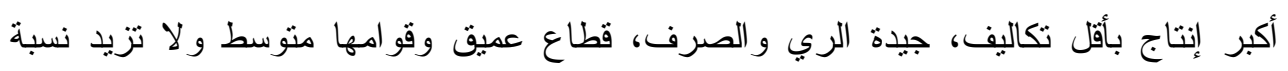

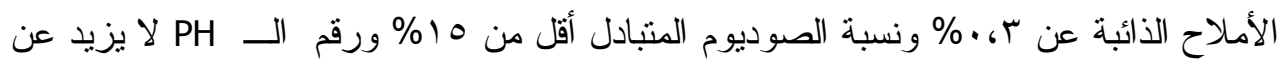

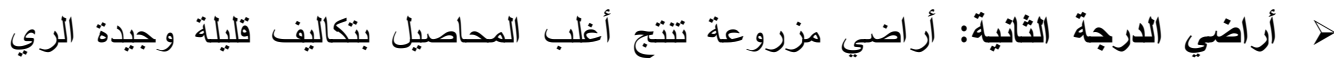

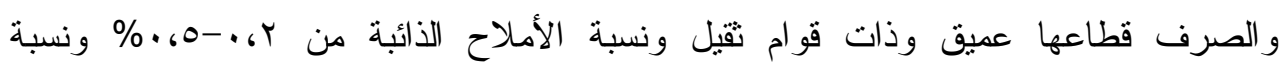

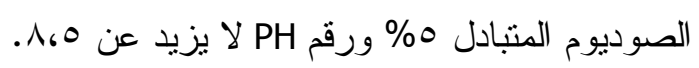

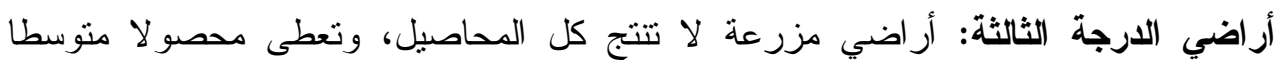

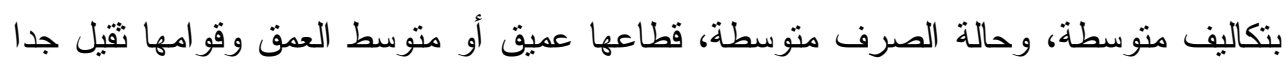

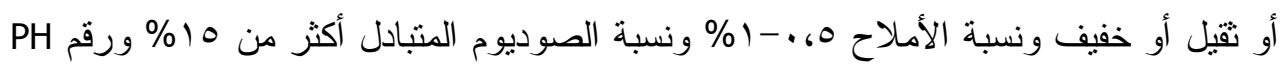

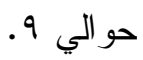
أراضي الارجة الرابعة: أراضي مزروعة أو تحت الاستزراع، محددة الإنتاج أو تصلح للإنتاج

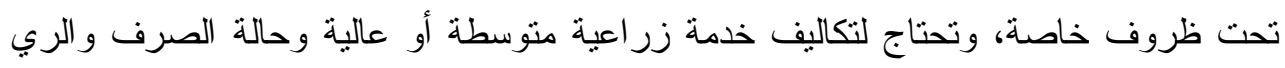

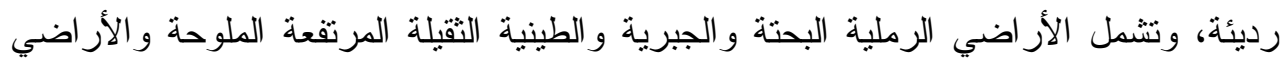

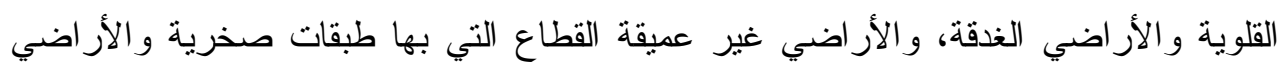

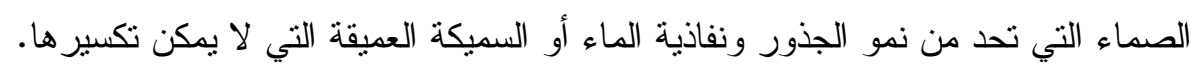

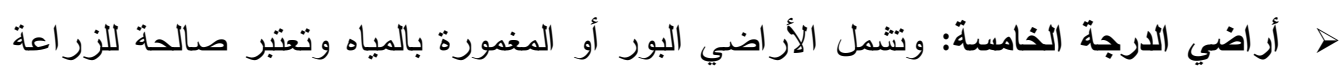
بعد استصلاحها. > أراضي الدرجة السادة: هي أراضي غير صالحة للزر اعة مثل الأراضي الصخرية والكثبان

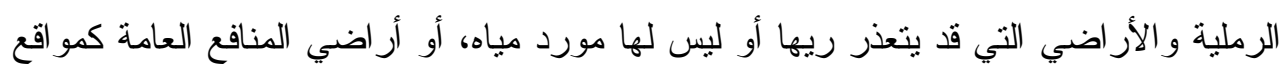

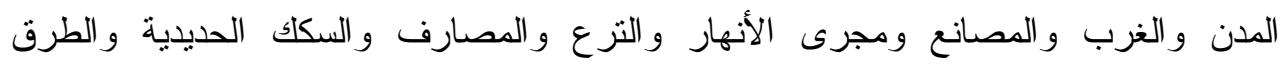

\section{نتائج الار اسة}

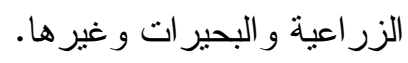

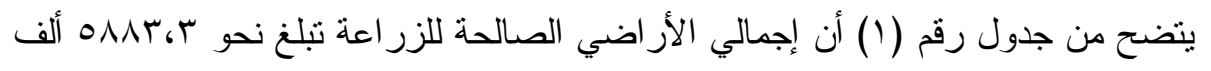

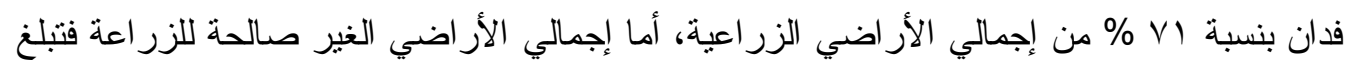

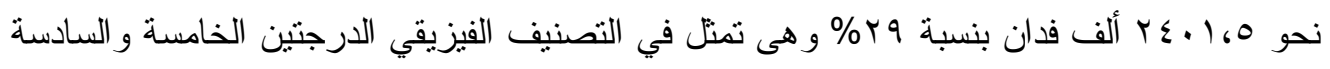




\begin{tabular}{|c|c|c|}
\hline \% من إجمالي المساحة المزروعة & المساحة ( ألف فدان ) & الدرجة النصنيفية \\
\hline$\varepsilon_{6}$ & $r 0967$ & الأولى \\
\hline M 1, A & & 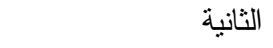 \\
\hline$r v_{6} v$ & rYq167 & 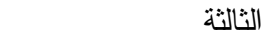 \\
\hline$V_{6} r$ & $091 . \mathrm{V}$ & 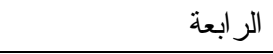 \\
\hline 1967 & $17 r 0.9$ & 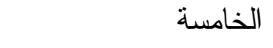 \\
\hline $9 ، \varepsilon$ & VYo.7 & 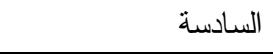 \\
\hline $1 \ldots$ & $\wedge r \wedge \varepsilon_{6} \wedge$ & الإجمالي العام \\
\hline
\end{tabular}

المصدر: جمعت وحسبث من بيانات وزارة الزر اعة واستصلاح الأراضي، الإدارة العامة للأراضي، قسم حصر الأر اضي، التصنيف الفيزيقي للأر اضي الزر اعية في مصر.

\section{التعليات على الأراضي الزراعية}

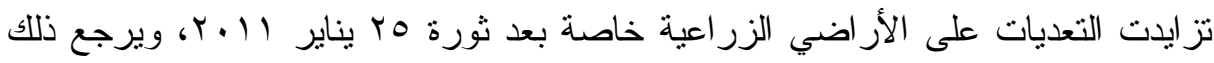

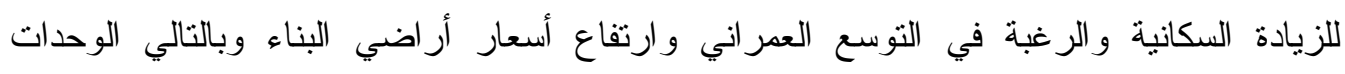
السكنية، بالإضافة لعدم الالتز ام بالقو انين.

ويوضح جدول رقم (r) أن إجمالي المساحات التي تم التعدي عليها في الفترة من هب بن بناير

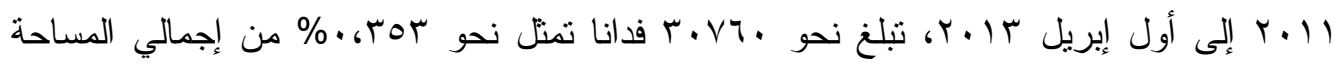

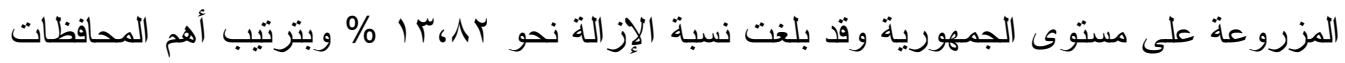

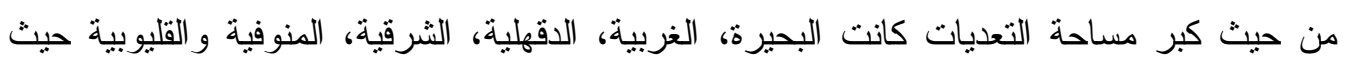

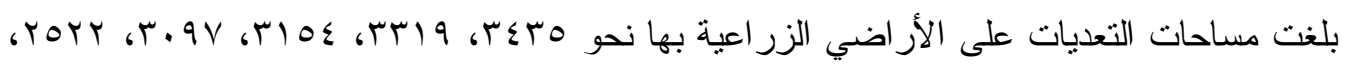

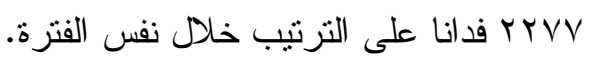
أنواع التعديات على الأراضي الزراعية

يمكن تقسيم التعديات على الأراضي الزراعية إلى ثلاثة أنىاعلهاع هي : حالات التعدي البسيطة و المتوسطة و الجسيمة. () التعديات البسيطة: تبوير الأرض و عدم زر اعتها تمهيدا للبناء عليها أو عمل أسوار حولها وغالبا ما تقع هذه الأر اضي على الطرق الزر اعية المؤدية للمدن أو بالأحرى على أطر اف الفئه المدن.

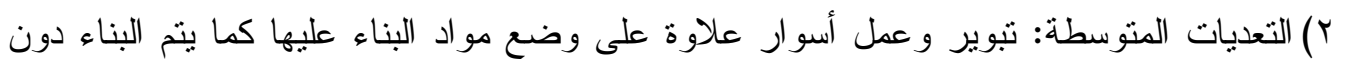
استكماله مع عدم وجود مر افق. r) التعديات الجسيمة: ويقصد بها اكتمال البناء وتوصيل المر افق بل وتصبح صعبة صعبة الإزالة لوجود

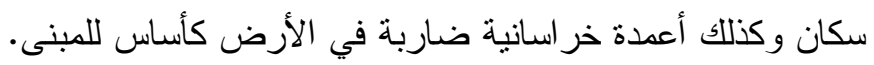


جدول رقم (Y): إجمالي المساحات التي نم التعدي عليها والأهمية النسبية للمساحة التي تم إز التها

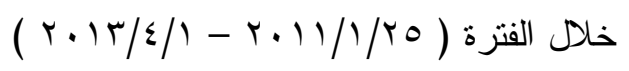

\begin{tabular}{|c|c|c|c|c|}
\hline من إجمالي التعدية النية النسبية & التساحة التي تم إز الة & الأهمية النسبية لمساحة & مساحة & المحافظة \\
\hline $11.1 \mathrm{~V}$ & rᄉs & $\cdot 6 \varepsilon$ & $r \leqslant r_{0}$ & البحيرة \\
\hline$q_{6} \cdot r$ & r.. & $\cdot 6 \cdot \varepsilon$ & 9 וسי & الغربية \\
\hline $1.69 V$ & $r \leq 7$ & $\cdot 6.4$ & Mos & الدقهلية \\
\hline$r \cdot 6 \wedge 0$ & $7 \leq 7$ & . & r. qV & الشرقية \\
\hline 0.49 & דy & $\cdot . \cdot r$ & rOYY & المنوفية \\
\hline$\Lambda_{G} r \leqslant$ & 19. & $\cdot . \cdot r$ & TrVV & القليو بية \\
\hline rr.Ao & 097 & $.6 . Y$ & $|\wedge| \varepsilon$ & المنيا \\
\hline IA.Ar & $r \cdot 1$ &..+1 & 1099 & أسيوط \\
\hline 0.74 & 10 & .6 .1 & 10.9 & كفر الثيخ \\
\hline $1 r_{6} \cdot 1$ & IVT & $\cdot 6.1$ & $1 \leqslant r r$ & قنا \\
\hline $10, \mathrm{VA}$ & $r \cdot T$ & $\cdot 6.1$ & $1 \pi .0$ & سو هاج \\
\hline$\left.\sum r_{6}\right) 1$ & $\{1$ & $\cdot .+1$ & $9 \vee 7$ & الأقصر \\
\hline$V_{6} \leqslant 1$ & $v \cdot$ & .6 .1 & $9 \leq \varepsilon$ & الفيوم \\
\hline r.M & r & .6 .1 & 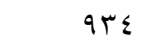 & بني سويف \\
\hline 7.49 & or & $\cdot 6 \cdot 9$ & NrT & دمياط \\
\hline$r \cdot \sigma r$. & $|r|$ & $\ldots 7$ & 097 & الجيزة \\
\hline $1 \leq 6 \vee 1$ & 71 & $\ldots .0$ & $\sum T r$ & الإسكندرية \\
\hline Mr.OV & $\varepsilon r$ & $\cdots, \ldots 1$ & Tr & الإسماعيلية \\
\hline E, & o & 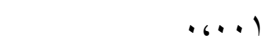 & $|r|$ & القاهرة - حلو ان \\
\hline $1 \pi, 14$ & $1 \varepsilon$ & $\ldots \cdot 1$ & 1.1 & أسوان \\
\hline $7 \leqslant 619$ & 71 & 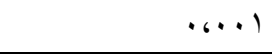 & $9 \leqslant$ & السويس \\
\hline $0, \leqslant V$ & $\varepsilon$ & - & Vr & شمال سيناء \\
\hline- & - & - & $r$. & بورسعيد \\
\hline $\mathrm{VA}, 0 \mathrm{~V}$ & 11 & - & $1 \leqslant$ & مرسى مطروح \\
\hline- & - & - & 1 & الو ادي الجديد \\
\hline Ir.AT & $\leq Y 0 \leq$ & . rTOK & $r \cdot v \tau$. & الإجمالي \\
\hline
\end{tabular}

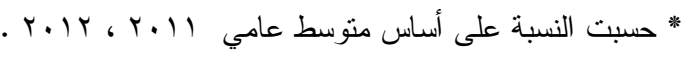
* تم تقريب المساحة لأقرب وحدة

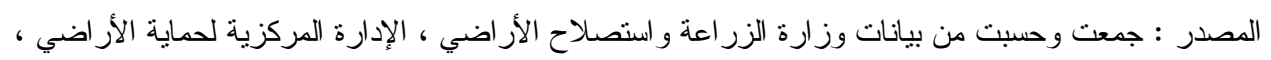

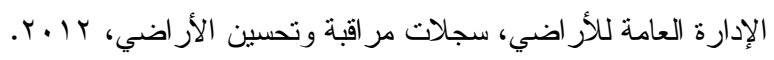


ويوضح جدول رقم (r) الأهمية النسبية لهذه الحالات الثناث من إجمالي مساحات التعدي على مستوى الوجهين البحري و القبلي و المحافظات ذات الأر اضي الرملية والمطرية خلال الفترة

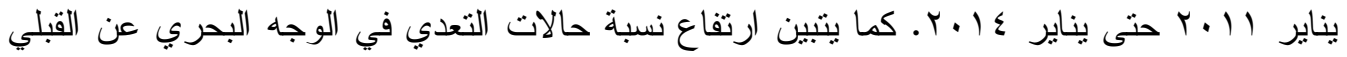

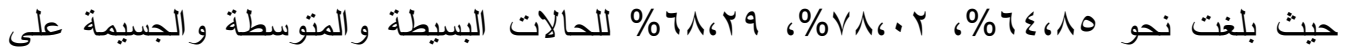

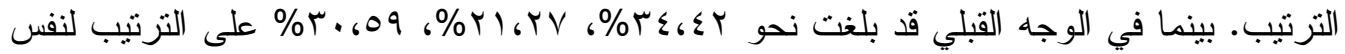
الحالات وكانت النسب منخفضة جدا في المحافظات ذات الأراضي الرملية والمطرية حيث بلغت

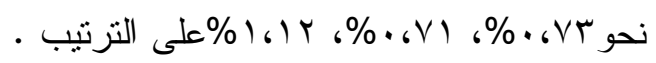
ومما سبق يتضح أن الوجه البحري مرتفع النسبة بكل أنواع التعديات فالبسيطة

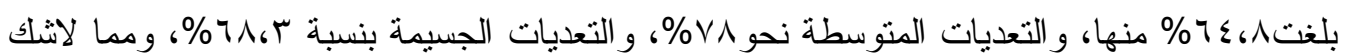
فيه أن معظم الأراضي الزراعية التي تم التعدي عليها تكون على طرق ممهدة وطرق مواصنات واصلات وعلى أطر اف القرى، ومعظم هذه الأر اضي التي تم التعدي عليها من أجود الأراضي خصوبة لاضية ولا جدول رقم (r) : الأهمية النسبية لأنواع التعديات على الأر اضي الزر اعية بالوجهين البحري و القبلي

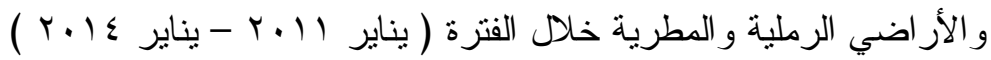

\begin{tabular}{|c|c|c|c|}
\hline \% الأر اضي الرملية و المطرية & \% الوجه القبلي & \% الوجه البحري & حالات التعدي \\
\hline $.6 \mathrm{VT}$ & $r \leq \varepsilon \leq r$ & $7 \leqslant 6$, 10 & بسيطة \\
\hline . . V & YI,TV & $V \Lambda_{6} \cdot r$ & متوسطة \\
\hline 1,15 & $r .69$ & $7 \Lambda_{6} Y_{9}$ & يمة \\
\hline
\end{tabular}

المصدر : جمعت وحسبت من بيانات وزارة الزر اعة و استصلاح الأراضي، الإدارة المركزية لحماية الأراضي.

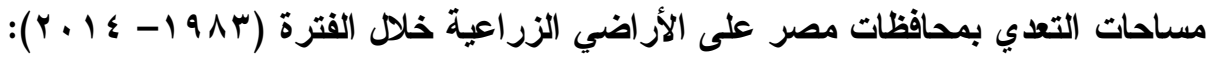

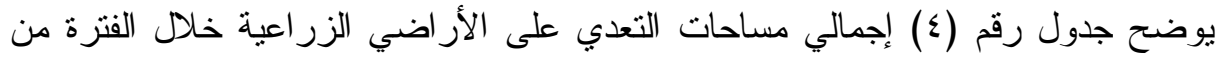

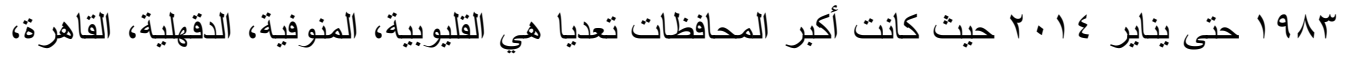

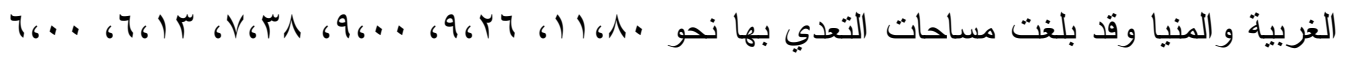
ألف فدان على التزتيب، وقد بلغت إجمالي المساحة المتعدى عليها خلال الفترة من سمو1 أنتى يناير

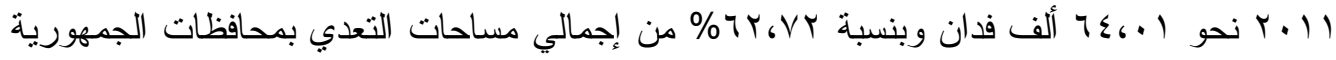

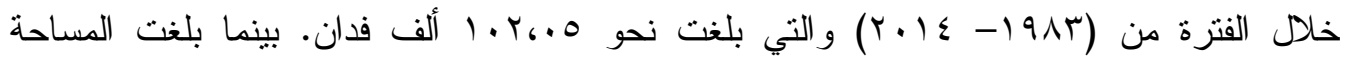

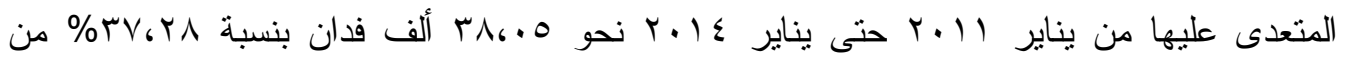

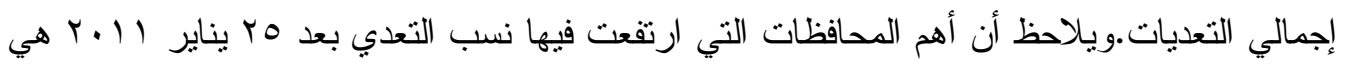

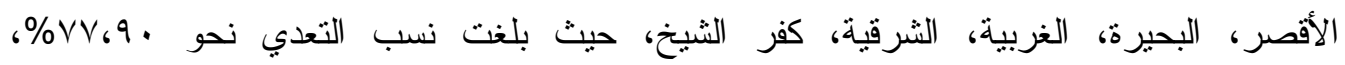

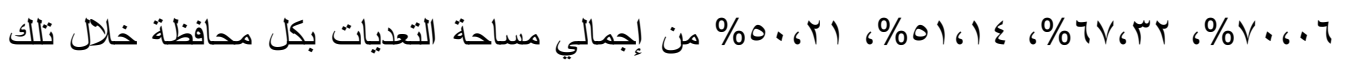

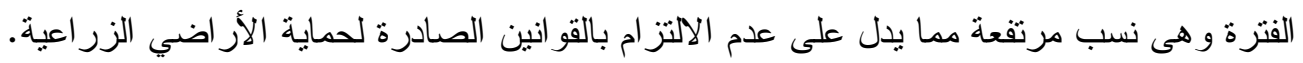


جدول رقم (ع): الأهمية النسبية لمساحة التعدي على الأر اضي الزر اعية

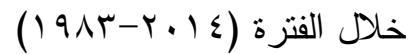

\begin{tabular}{|c|c|c|c|c|c|}
\hline تعديات (يناير ل الأهمية النسبية لمساحة & 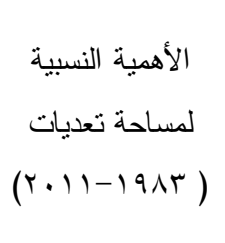 & الإجمالي & 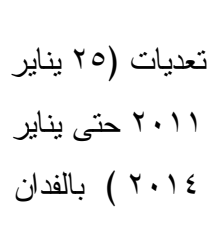 & 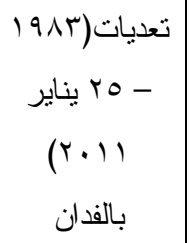 & المحافظة \\
\hline$V \cdot 6 \cdot 7$ & Y9.9 & $0 \wedge 9$. & 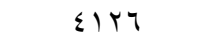 & $1 V 7 \varepsilon$ & البحيرة \\
\hline TVGrT & Tr.tA & TITO & EIrT & $r \ldots r$ & الغربية \\
\hline rq. vo & T. . TO & $q \ldots r$ & rove & $0 \leqslant r_{0}$ & الدقهلية \\
\hline $01,1 \leq$ & $\sum \Lambda_{6} \wedge \uparrow$ & 0711 & TAVT & $r V \leqslant 0$ & الشرقية \\
\hline$\varepsilon r_{6} \cdot \varepsilon$ & $0 V .97$ & grov & ए人9) & דידוס & المنوفية \\
\hline ro، $\varepsilon \wedge$ & $V \varepsilon$ \& Or & 11897 & r. o & $\wedge \vee q 1$ & القليوبية \\
\hline r & $70, \mathrm{TV}$ & $7 \ldots 1$ & $r \cdot \Lambda$. & rark & المنيا \\
\hline$\varepsilon 1,7 r$ & ON, MN & $\varepsilon \Lambda \cdot \varepsilon$ & 1999 & $r \wedge .0$ & أسيوط \\
\hline 0.641 & $\leqslant 9, \vee 9$ & or $\leq 7$ & rTrE & ryוr & كفر الثيخ \\
\hline rT, & $T V_{6}$ AV & ¿qr. & $101 \varepsilon$ & Tr & قنا \\
\hline ro,rt & $T \varepsilon_{6} V V$ & 0007 & $190 \mathrm{~V}$ & ro99 & سو هاج \\
\hline VV.q. & $\left.r_{6}\right)$. & 1111 & NTV & $r \leq T$ & الأقصر \\
\hline$\varepsilon \varepsilon \sigma \vee$. & $00,1$. & rNI. & IroT & $100 \leqslant$ & الفيوم \\
\hline$\leq 0,0 r$ & $0 \leqslant ، \leqslant \Lambda$ & r. 9 & $1 \leq 10$ & $179 \leq$ & بني سويف \\
\hline T1.11 & 71,199 & $r \cdot v r$ & 907 & rIIV & دمياط \\
\hline $1.6 \leq 0$ & 19,00 & 0719 & $09 \varepsilon$ & 0.90 & الجيزة \\
\hline $176 . \varepsilon$ & Nr.97 & rVrq & 091 & וTוM & الإسكندرية \\
\hline $0.6 \leqslant r$ & $\sum 9.0 \mathrm{~V}$ & rov & 11. & IVV & الإسماعيلية \\
\hline r.01 & $9 V_{6} \leq 9$ & VTVT & 110 & 191 & القاهرة \\
\hline ro,vo & $V \leqslant$ r YO & 0.1 & 149 & rVT & أسو ان \\
\hline rr.os & $V V_{6} \leq 7$ & $v_{1}$ & 17 & 00 & السويس \\
\hline TV.rA & TYGVT & $1 . r .09$ & $r \Lambda \cdot \leq T$ & $T \varepsilon \cdot 1 T$ & الإجمالي \\
\hline
\end{tabular}

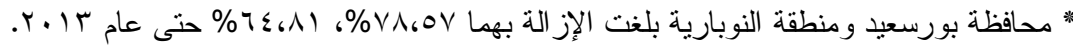

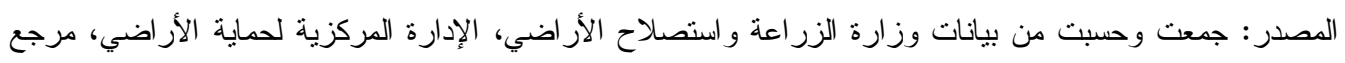




\section{الأثر الاقتصادي للتعديات على الأراضي الزراعية :}

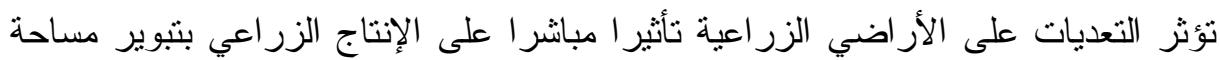

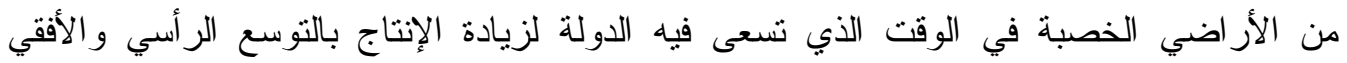

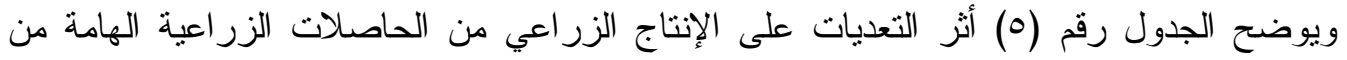
حيث الخسارة في الإتتاج وإجمالي العائد. وقد تم تقسيم التحليل الوصفي إلى فترتين (raA أ- يناير

(1)

جدول رقم (0): اثر التعديات على الأر اضي الزر اعية على الإنتاج الزر اعي لبعض الحاصلات

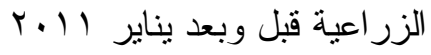

\begin{tabular}{|c|c|c|c|c|c|c|}
\hline \multicolumn{3}{|c|}{ 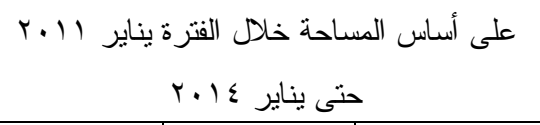 } & \multicolumn{3}{|c|}{ 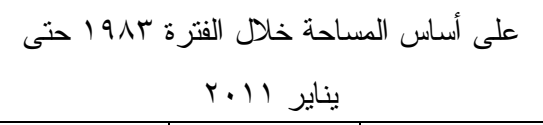 } & \multirow[b]{2}{*}{ البيان } \\
\hline 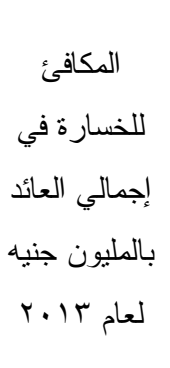 & 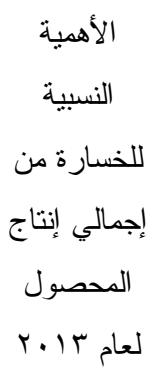 & للإل الإنتاج بالألف في & اللخسارة الجمالي العيائد & 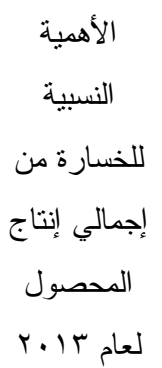 & لل للخسارة في الإنتاج بالألف & \\
\hline$r \leqslant 0$ & 1615 & 1.7 .05 & 011 & 1.19 & $1 V 9, r \varepsilon$ & القمح \\
\hline rrI & 15,47 & $r \leq 6, T \leq$ & $0 \leqslant 1$ & rtGrt & $O V(7)$ & القطن \\
\hline ع & r.TV & $10 r_{611}$ & $07 r$ & $\varepsilon, 0 \leqslant$ & roT... & الأرز \\
\hline rov & 11,00 & IArr.s. & 11.7 & 19.77 & r.T.Tr & قصب السكر \\
\hline Trt & $\Lambda_{6} Y_{7}$ & 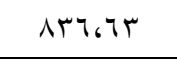 & $0 \leq \leqslant$ & 1569. & $1 \leq .16 \wedge 1$ & بنجر السكر \\
\hline r9o & $1.9 \mathrm{~V}$ & $1 Y 0,00$ & ¿qV & $r, r)$ & 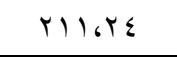 & الذرة الثشامية \\
\hline 007 & T.V $\varepsilon$ & DKr, & 970 & $\{$ \{7) & 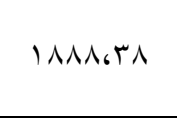 & 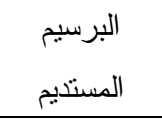 \\
\hline rVV & $r 4,71$ & $O V_{6} \cdot V$ & $\leq 77$ & $71,7$. & $97 . .4$ & الفول البلدي \\
\hline
\end{tabular}

المصدر : جمعت وحسبت من بيانات وزارة الزر اعة واستصلاح الأراضي، الإدارة المركزية للاقتصاد الزر اعي، نشرة

الاقتصاد الزر اعي، أعداد مختلفة.

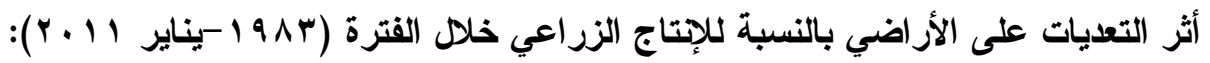

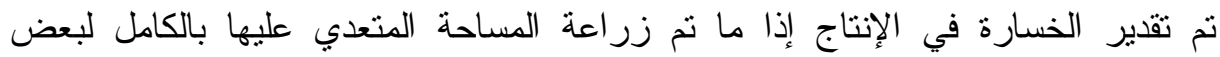

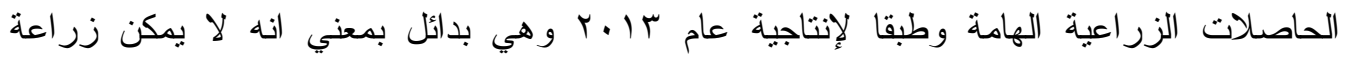

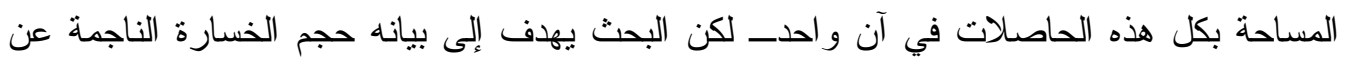

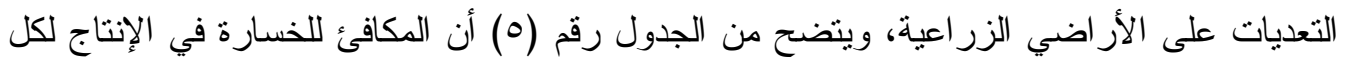




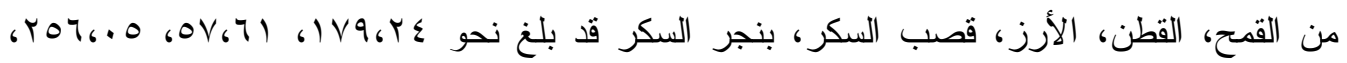

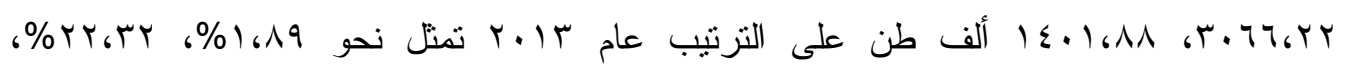

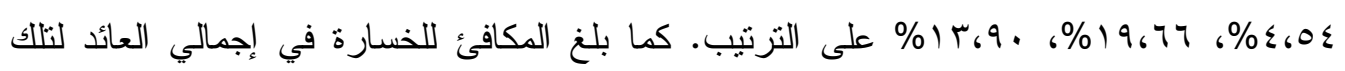

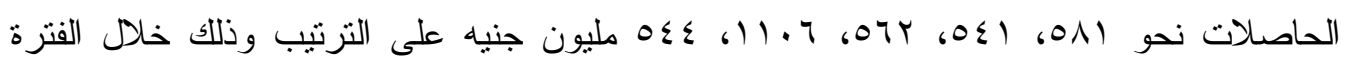

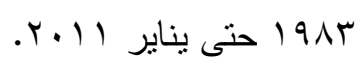
كما يتضح أيضا من الجدول رقم (ه) أن المكافئ للخسارة في الإنتاج لكل من الذرة الثامية،

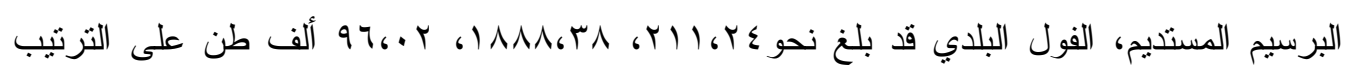

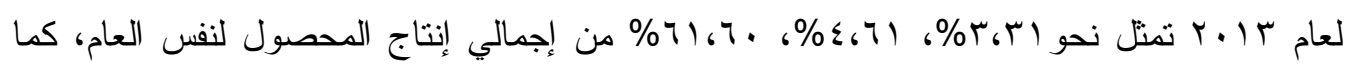
بلغ المكافئ للخسارة في إجمالي العائد الفدانى نحو

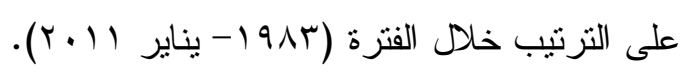

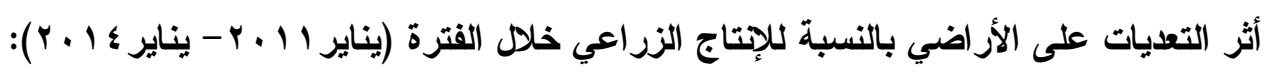

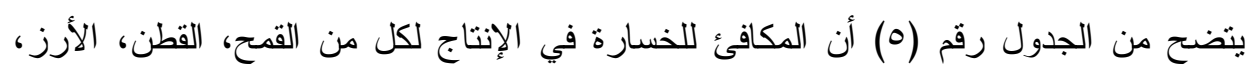

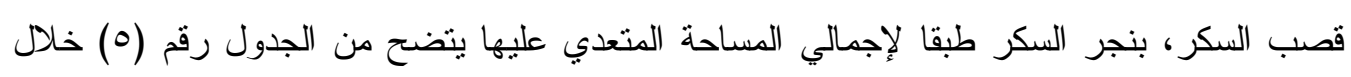

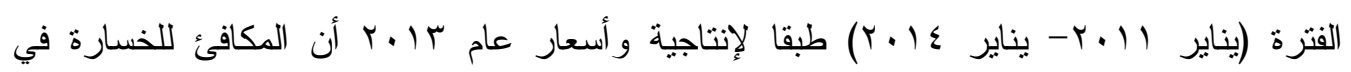

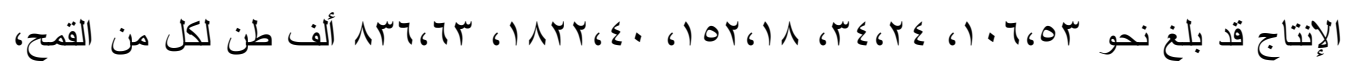

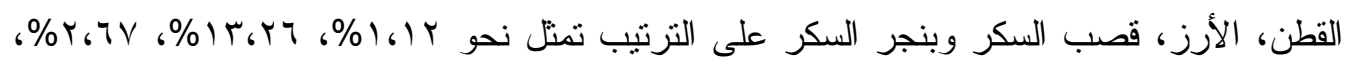

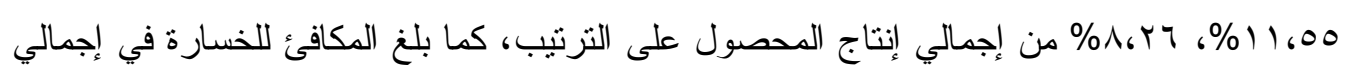

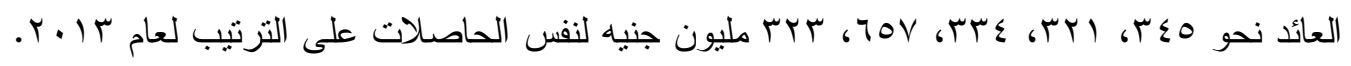

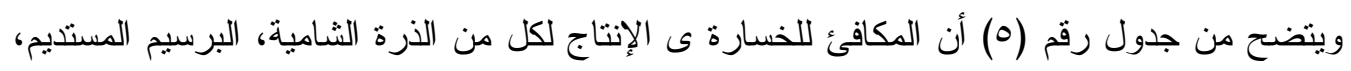

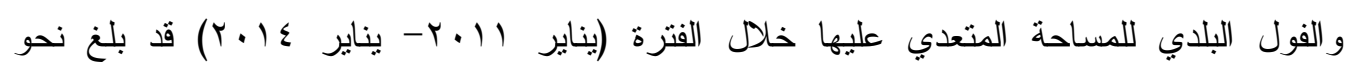

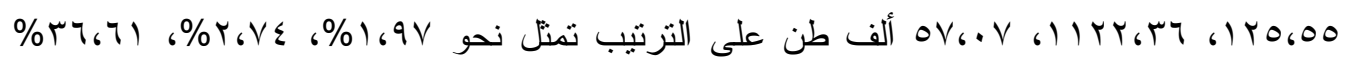

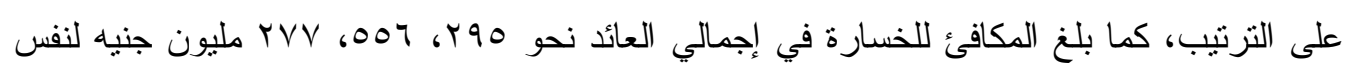

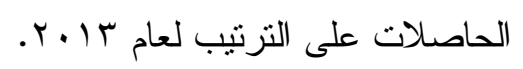

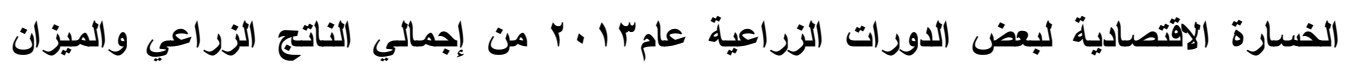
الزراعي:

تم تقدير الخسارة الاقتصادية الناجمة عن التعديات على الأراضي الزراعية للمساحة الكلية

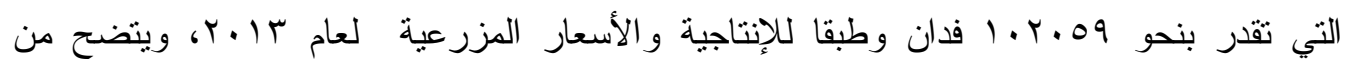

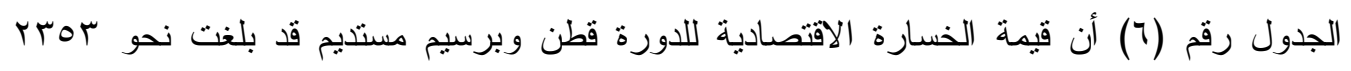

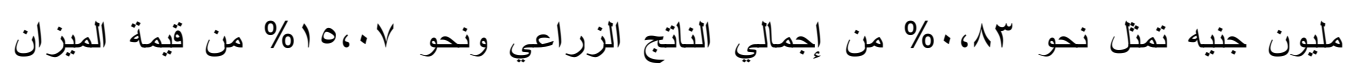

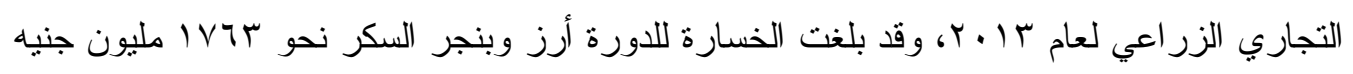




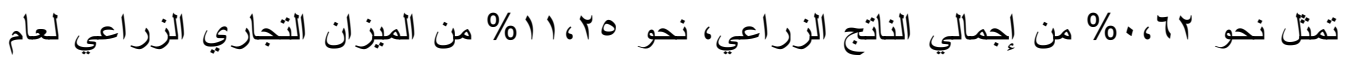
.$+1 T$

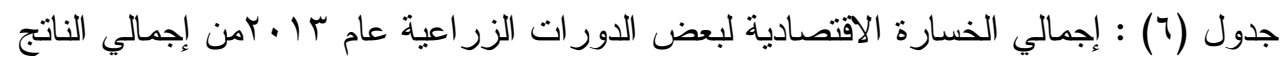

\begin{tabular}{|c|c|c|c|c|c|c|c|}
\hline \multicolumn{8}{|c|}{ الزر اعي و الميز ان التجاري الزر اعي } \\
\hline \multicolumn{3}{|c|}{ 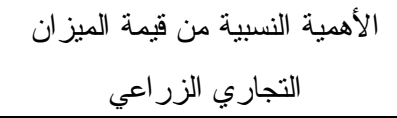 } & \multicolumn{3}{|c|}{ الأهمية النسبية لإجمالي الناتج } & \multirow{2}{*}{ قالاقتصادية مليون } & \multirow{2}{*}{ 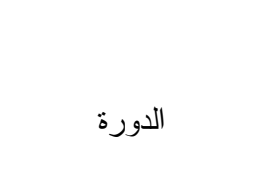 } \\
\hline$r .14$ & $r \cdot r^{2}$ & $r \cdot 11$ & $r \cdot 1 r$ & $r \cdot i r$ & $r \cdot 11$ & & \\
\hline $10 . . \mathrm{V}$ & rr..O & $v_{6} 7$. & 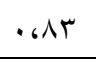 &.$\triangleleft \wedge \mathrm{V}$ & .69 & rrot & قطن و برسيم مستخيم \\
\hline $11, r_{0}$ & 17.04 & 0.79 & זדים & . 670 & . rV. & 1V4T & أرز و بنجر السكر \\
\hline $116 .$. & 1761. & 0,00 & $\cdot 67$ & .670 & .671 & $|V| \Lambda$ & ذرة شامية و قمح \\
\hline $1.6 \mathrm{rA}$ & 106. & 0,11 & .07 & .67 & $.7 \varepsilon$ & 17.0 & قطن و فول بلدي \\
\hline 1.67 & 10,00 & 0,47 & .01 & צTה. & 747.6 & 1709 & ذالسكرة شامية وبنجر \\
\hline $11,7 \mathrm{~V}$ & $1 v_{6} \cdot 1$ & $0, \wedge \Lambda$ & . & .671 &. . VY & IATr & أرز و قمح \\
\hline
\end{tabular}

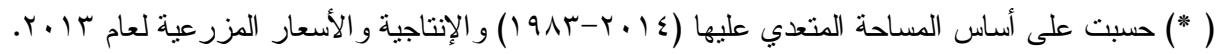

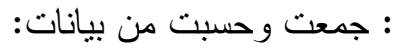

1- وزارة الزراعة واستصلاح الأراضي ، الإدارة المركزية للاقتصاد الزراعي ، نشرات الاقتصاد الزر اعي ، أعداد مختلفة.

r- الجهاز المركزي للتعبئة العامة و الإحصاء ، النشرة الاقتصادية السنوية ، أعداد مختلفة .

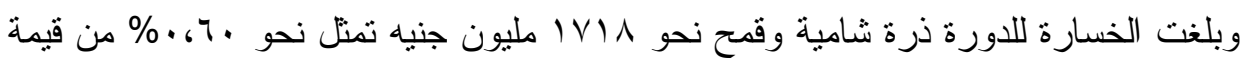

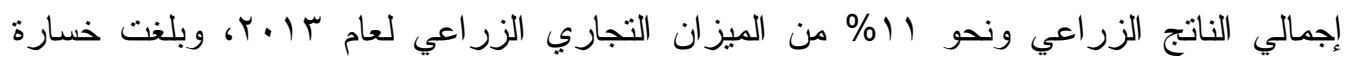
الدورة قطن وفول بلدي نحو 17 . مليون جنيه نمتل نحو 07، •\% من قيمة إجمالي الناتج

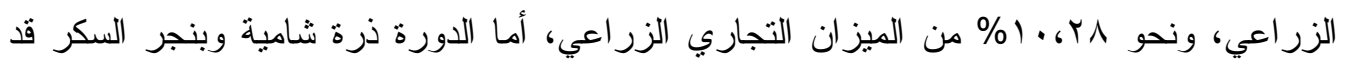

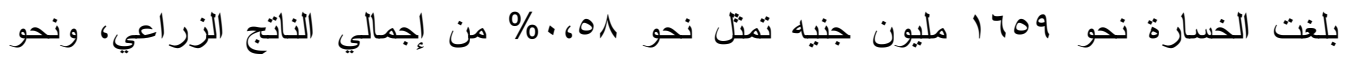

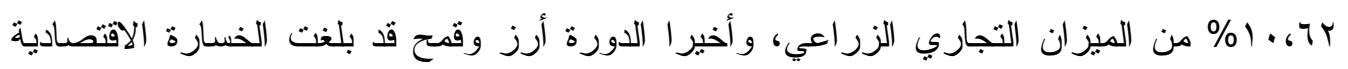

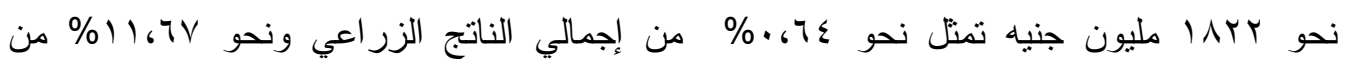
الميز ان التجاري الزر اعي. ويلاحظ أن اكبر الخسائر كانت في دورة القطن و البرسيم المستديم بليها

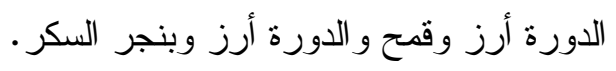




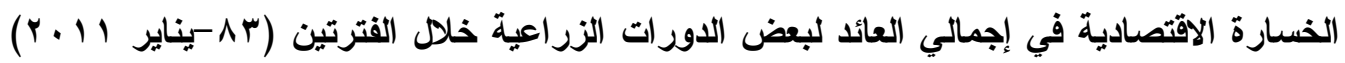

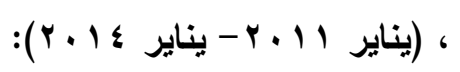

يتضح من الجدول رقم (V) أن قيمة الخسارة للدورة الزر اعية قطن وبرسيم مستديم طبقا

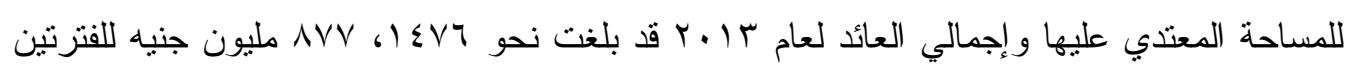

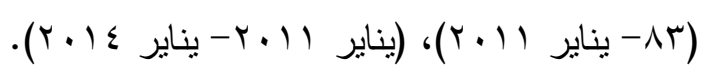

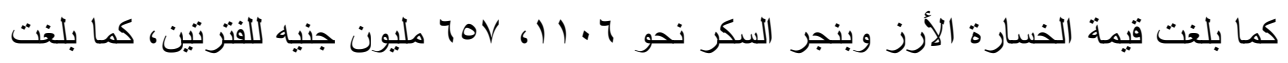

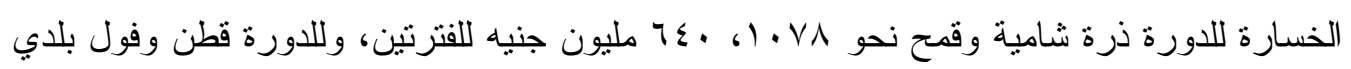

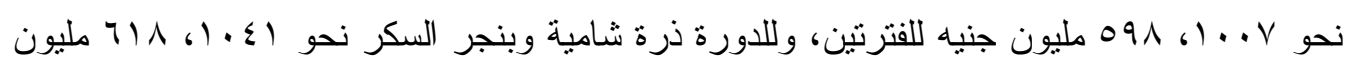

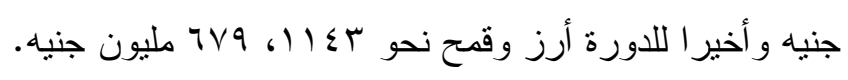
جدول (V): الخسارة الاقتصادية في إجمالي العائد للاورات المختلفة للمساحات المتعدى عليها خلا

\begin{tabular}{|c|c|c|c|c|}
\hline للخسارة في الفترة & اللخسارة الهمية النسبية & ع قيمة الخسارة للفترة & 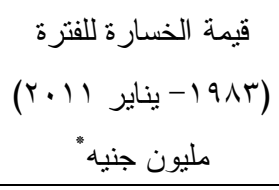 & الدورة الزر اعية \\
\hline TV.rA & TH.VT & AVV & $1 \leqslant V 7$ & قطن + برسيم مستديم \\
\hline MV. TV & Tr.VT & $70 \mathrm{~V}$ & 11.7 & أرز + بنجر السكر \\
\hline TV.rT & Tr.VE & $T \varepsilon$. & $1 . \vee \wedge$ & ذرة شامية + قمح \\
\hline rV, TT & Tr.VE & 091 & $\cdots v$ & قطن + فول بلدي \\
\hline TV.rT & Tr.VE & $71 \wedge$ & $1 . \leqslant 1$ & ذرة شامية + بنجر \\
\hline rV.rV & Tr.VT & $7 \vee 9$ & $11 \leqslant r$ & أرز + قمح \\
\hline
\end{tabular}

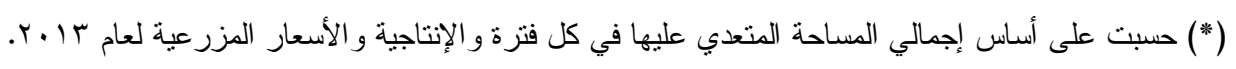
المصدر : جمعت وحسبت من بيانات: ا- وزارة الزراعة واستصلاح الأراضي ، الإدارة المركزية للاقتصاد الزراعي ، نشرات الاقتصاد الزراعي، أعداد مختلفة . r- الجهاز المركزي للتعبئة العامة والإحصاء ، النشرة الاقتصادية السنوية ، أعداد مختلفة .

الخسارة الاقتصادية للمساحة المتعدي عليها من إجمالي الصادرات والواردات الزراعية خلال الفترة

$$
:(r \cdot 1 \leq-r \cdot 11)
$$

يتضح من الجدول رقم (^) أن قيمة الخسارة الاقتصادية طبقا لإجمالي المساحة المتعدي عليها

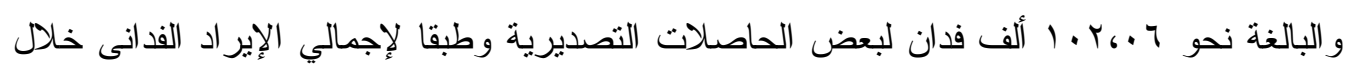

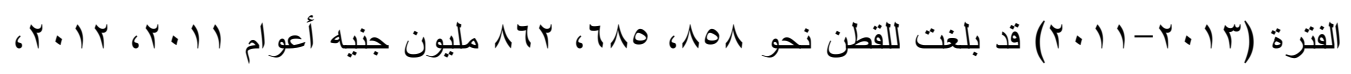




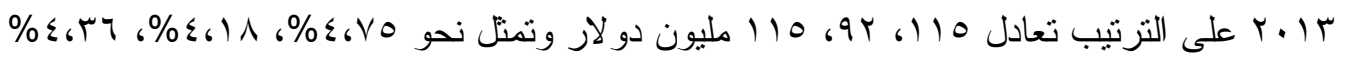

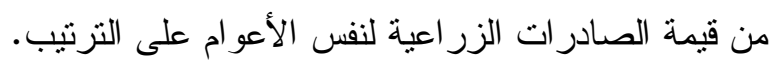

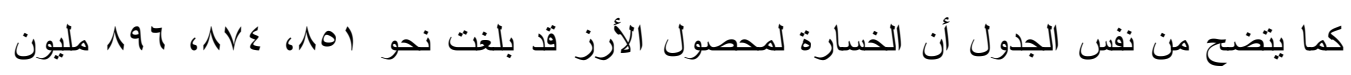

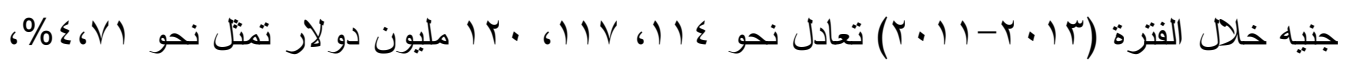

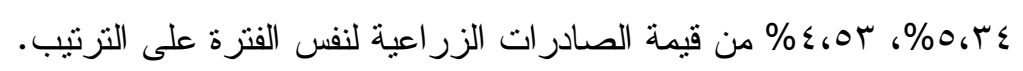

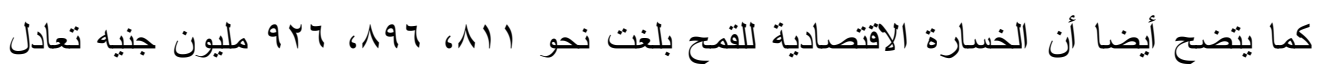

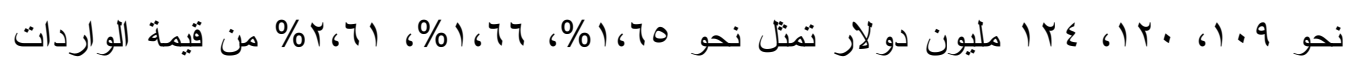

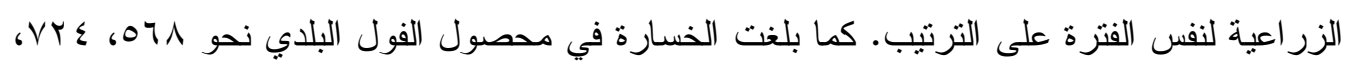

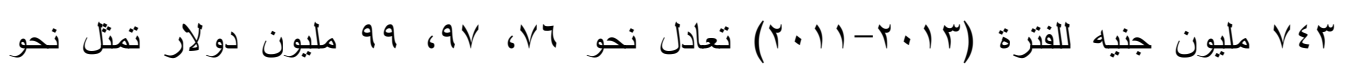

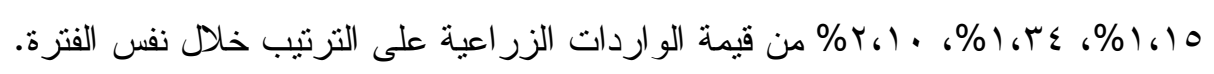

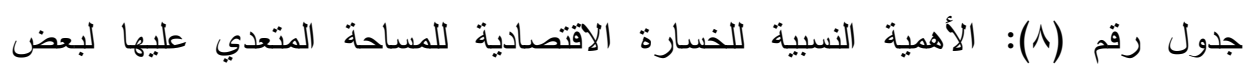

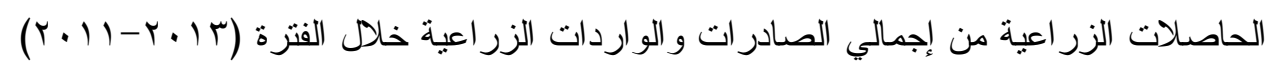

\begin{tabular}{|c|c|c|c|c|c|c|c|c|c|c|c|c|}
\hline \multicolumn{3}{|c|}{ الأهمية النسبية من قيمة } & \multicolumn{3}{|c|}{ الأهمية النسيية من قيمة } & \multicolumn{3}{|c|}{ الخسارة بالمليون جنيه" } & \multicolumn{3}{|c|}{ الخسارة بالمليون جنيه } & \multirow[t]{2}{*}{ المحصول } \\
\hline$r .1 r$ & $r .1 r$ & $r .11$ & $r .1 r$ & $r .1 r$ & $r .11$ & $r .1 r$ & $r .1 r$ & $r .11$ & $r .1 r$ & $r .1 r$ & $r .11$ & \\
\hline & & & & & & & & & & & & الصادرات \\
\hline & & & דום, & (6)1 & E,Vo & 110 & 94 & 110 & אוז & 710 & 101 & القطن \\
\hline & & & \&.0 & $0, r \varepsilon$ & $\varepsilon, V)$ & $k$. & $11 \mathrm{~V}$ & $11 \varepsilon$ & 197 & $\Lambda V \varepsilon$ & 101 & الأرز \\
\hline \multicolumn{13}{|r|}{ الو اردات } \\
\hline r.7T & 1.77 & 1.70 & & & & ITE & Ir. & 1.9 & 9Y7 & 197 & 111 & القمح \\
\hline$\left.r_{6}\right)$. & ع & 1610 & & & & 99 & १V & ז & $v \leqslant r$ & $V Y \leq$ & 071 & الفول \\
\hline & & & & & & & & & & & & البلدي \\
\hline
\end{tabular}

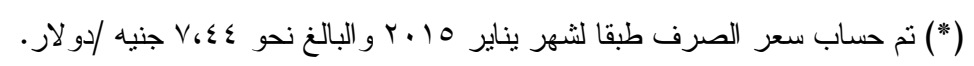
المصدر : جمعت وحسبت من بيانات:

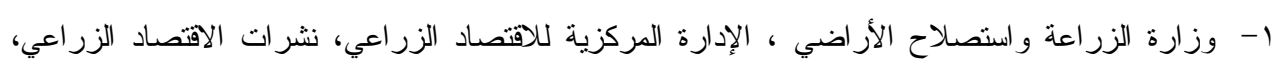
أعداد مختلفة . ץ- الجهاز المركزي للتعبئة العامة والإحصاء ، النشرة الاقتصادية السنوية ، أعداد مختلفة . الأثر الاجتماعي للتعديات على الأراضي الزراعية:

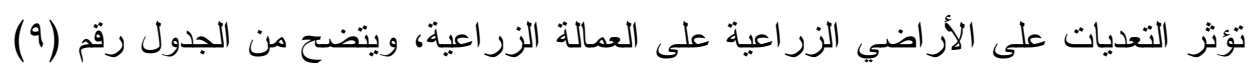

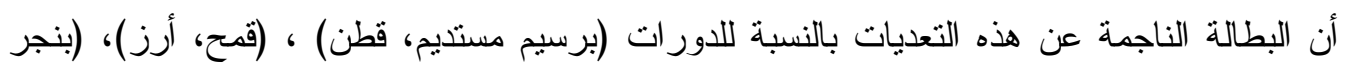

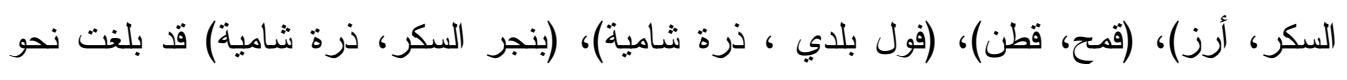

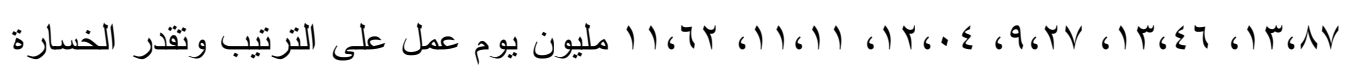




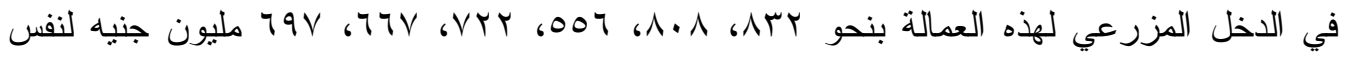

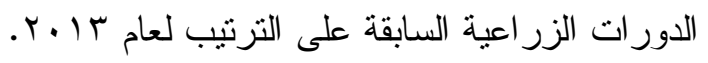
أي أن اعلي نسبة للبطالة هي في الدورة (برسيم مستديم، قطن) طبقا لإجمالي المساحة

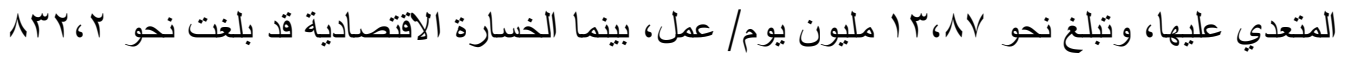

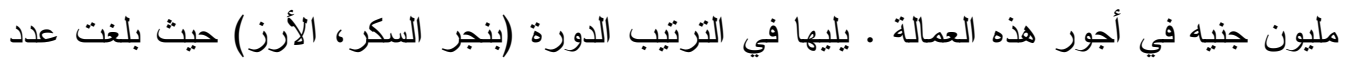
أيام البطالة حو الي جـ، با مليون عمل، وتليها دورة (فول بلدي، قطن) حيث بلغت عدد أيام البطالة

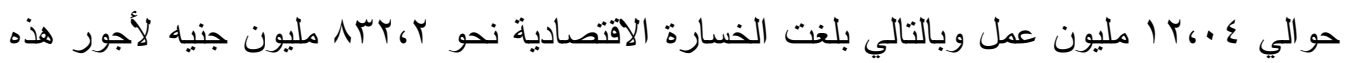
العمالة، AV، مليون جنيه، ع، YYY مليون جنيه لنفس الدورات السابقة على الترتيب. جدول رقم (9): الخسارة الاقتصادية للعمالة في بعض الدور ات نتيجة تعديات الأر اضي الزر اعية لهنه

\begin{tabular}{|c|c|c|}
\hline قيمة الخسارة في الدخل المزرعي" & عدد أيام البطالة" " مليون يوم/ عمل & الدورة الزر اعية \\
\hline Art & I r.AV & قطن وبرسيم مستديم \\
\hline$\wedge \cdot \wedge$ & $1 \pi, \varepsilon 7$ & أرز وبنجر السكر \\
\hline 007 & q.rV & ذرة شامية وقمح \\
\hline VYr & $M_{6} \cdot \varepsilon$ & قطن وفول بلدي \\
\hline TTV & 11611 & ذرة شامية وبنجر السكر \\
\hline $79 V$ & 11674 & أرز وقمح \\
\hline
\end{tabular}

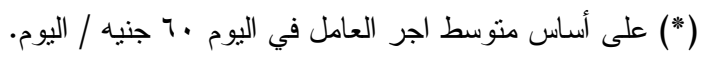

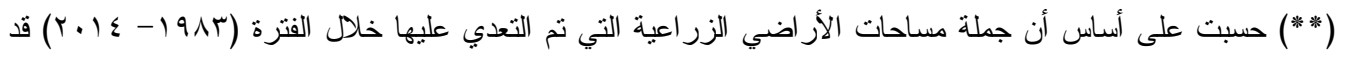

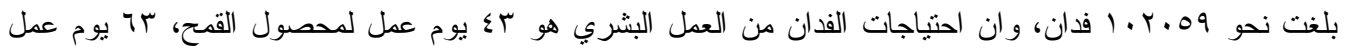

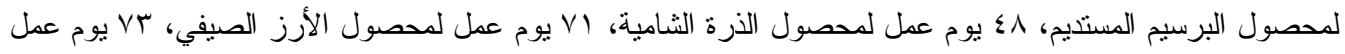

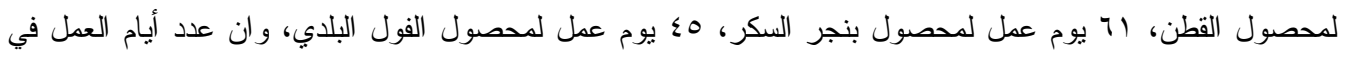

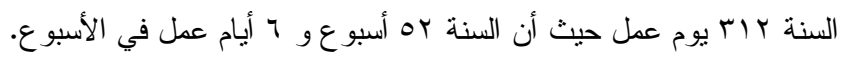
قو انين حماية الأراضي الزراعية :

صدرت العديد من القوانين المتعلقة بحماية الأراضي الزراعية من التبوير والتجريف، التهات

ورغم ذللك تم التعدي على بعض المساحات بمعظم محافظات مصر ، ومن هذه القو انين ما يلي:

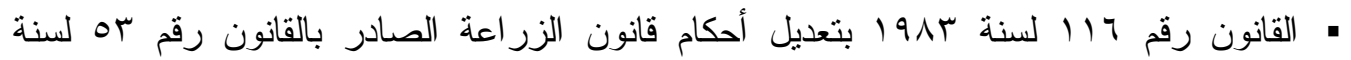
1974 بشأن عدم المساس بالرقعة الزراعية والحفاظ على خصوبتها وقد نص على الآتي :

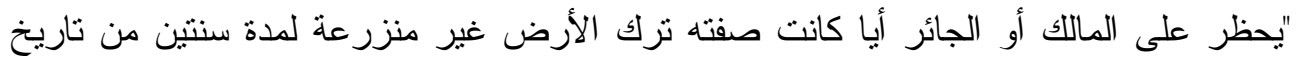

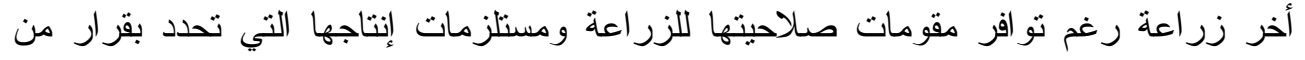
وزير الزر اعة، ويحظر عليه ارتكاب أي فصل أو الامتتاع عن أي عمل من شأنه بتبوير الأرض لوض

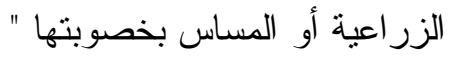




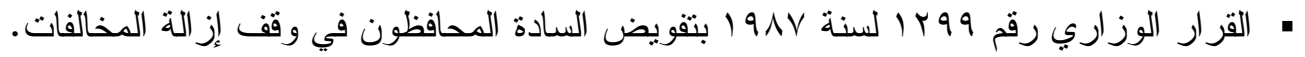

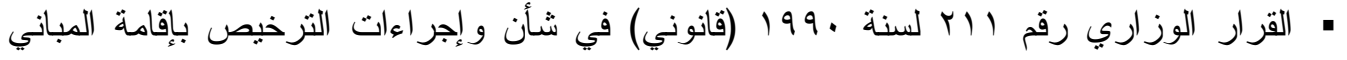

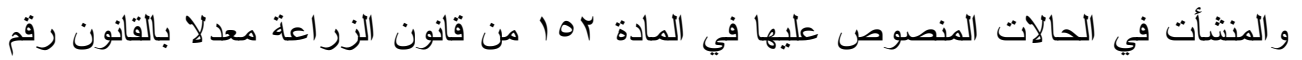
111 لسنة بر919 يضافا لقانون الزر اعة تحت عنوان عدم المساس بالرقعة الزر اعية والحفاظ على خصوبتها على نحو يشدد ويغلظ العقوبات التي رصدها لجر ائم التعدي على الرقعة الزر اعية

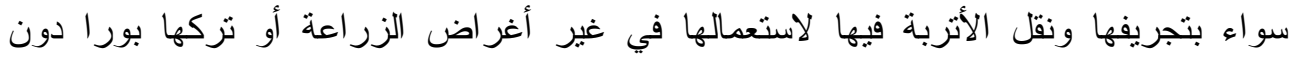

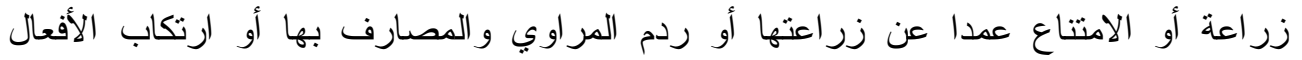

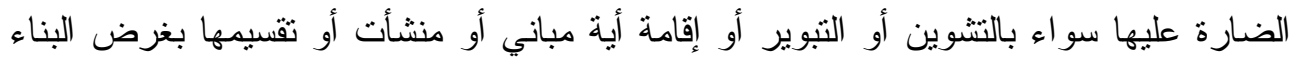

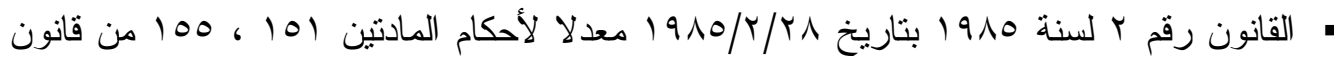

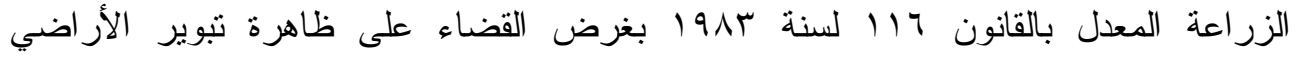
الزر اعية عمدا ووجوب إز الة أسباب التعدي بالطريق الإداري فور ا منعا من تفاقم المشكلة.

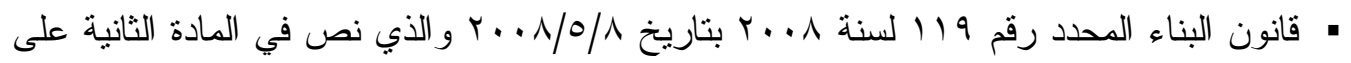

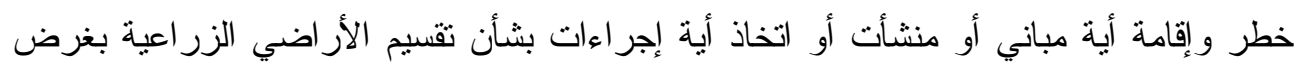

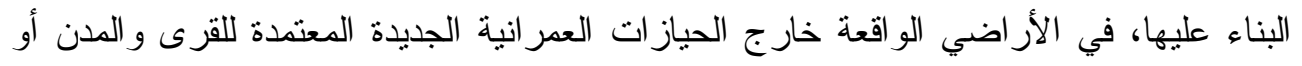

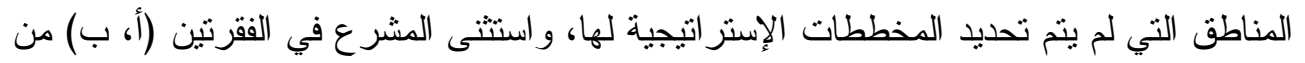

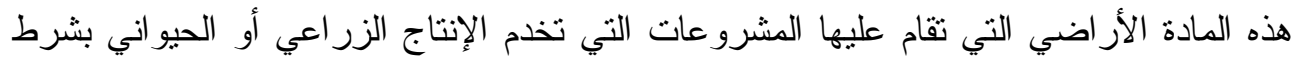

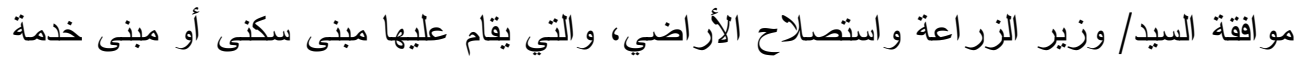

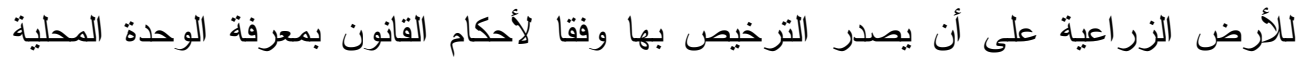

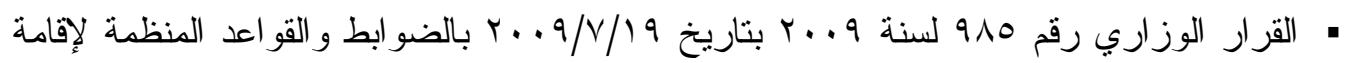
المباني و المنشأت على الأراضي الزراعية الواقعة خارج الحياز ات العمر انية الجديدة المعتمدة

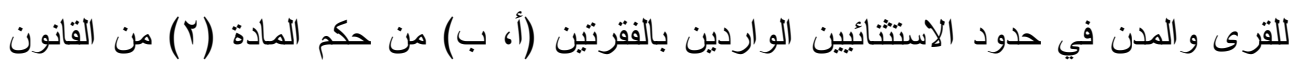

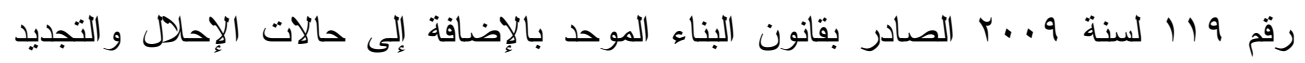
للمباني المقامة بالفعل قبل صدور أحكام هذا القانون بانشتر اطات وضو ابط محددة.

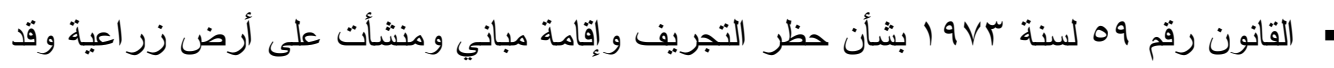

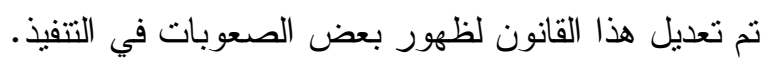
• القانون رقم 117 لسنة برد19 في شأن تعديل بعض أحكام قانون الزر اعة وجاء في أربعة مو اد

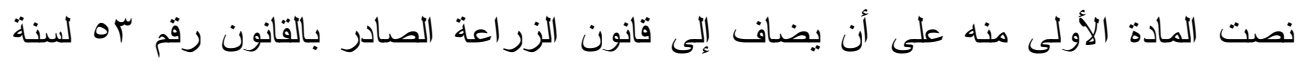

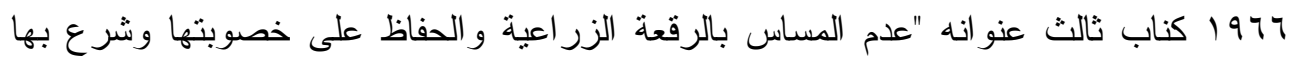
المو اد من ·10 إلى 109 الحماية الرقعة الزر اعية. 
• القرار الوزاري رقم ـ لسنة عـ919 (قانوني) بشأن تتظيم التراخيص بتجريف الأراضي

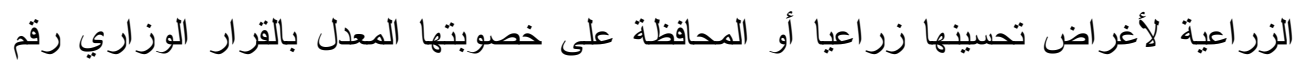

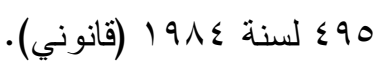

• القرار الوزاري رقم 1171 لسنة 1999 بشأن تحديد الحالات التي تقضى بتجريف الأرض

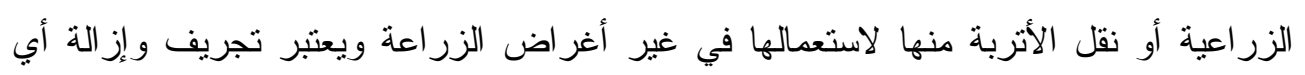

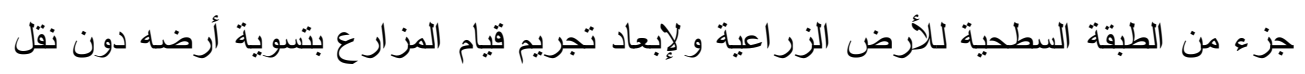
أي أثزبة منها.

\section{الملخص}

لقد بلغت المساحة المتعدي عيها بمحافظات الجمهورية نحو 09.؟ • 1. فدان خلال الفترة

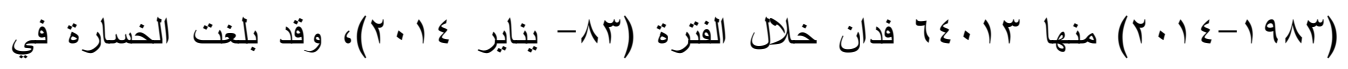

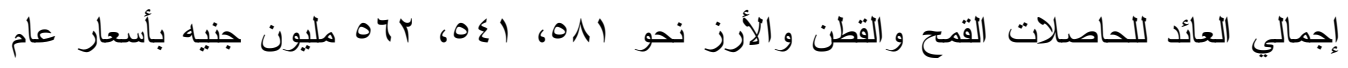

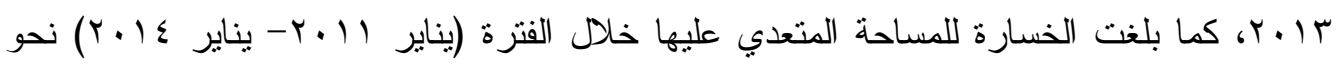

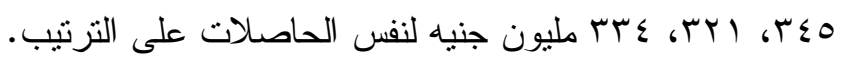
وقد بلغت الخسارة الاقتصادية أن إجمالي المساحة المتعدي عليها لبعض الدورات الزبه الزراعية

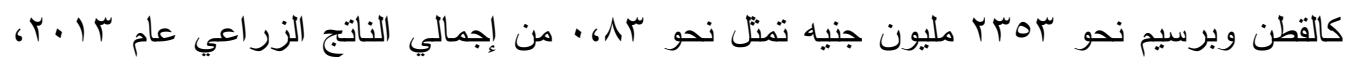

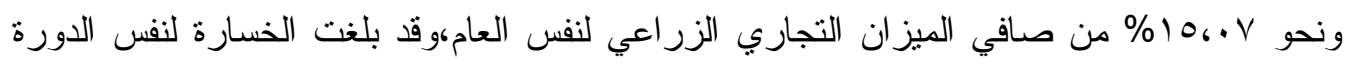

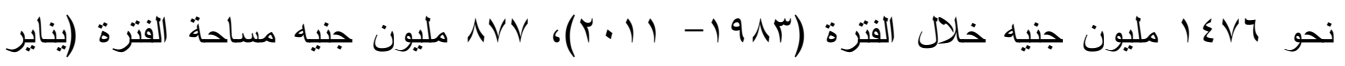

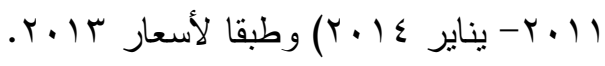

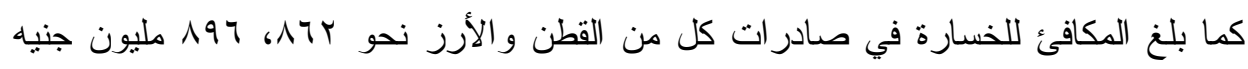

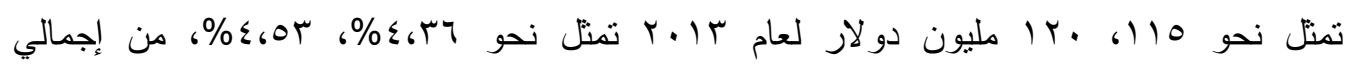

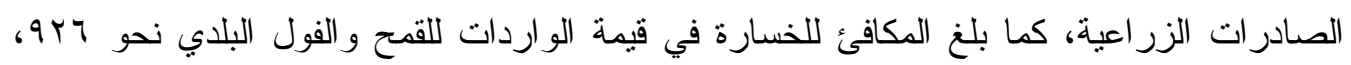

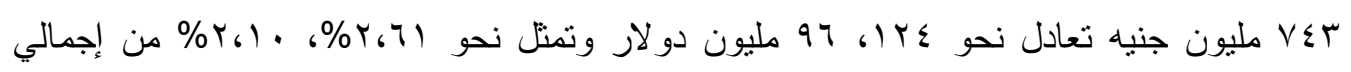

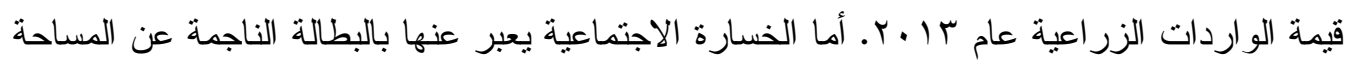

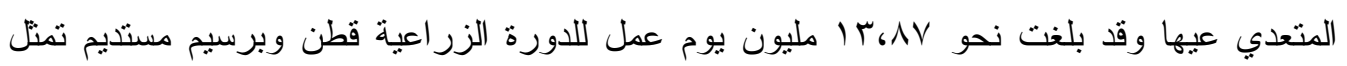

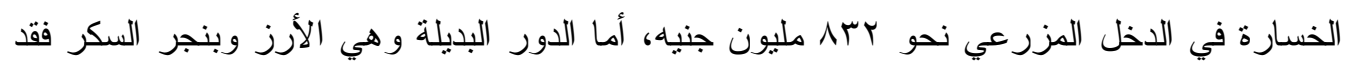

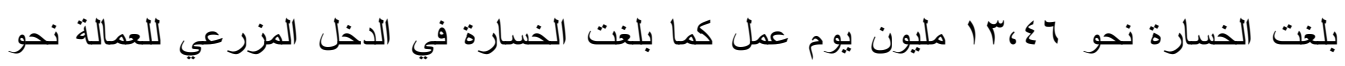
1 م مليون جنيه. 


\section{التوصيات}

• تشنديد العقوبات على المتعدين على الأراضي الزر اعية بالحبس و الغر امة معا .

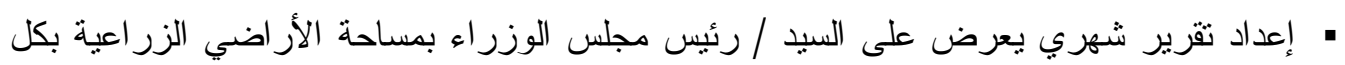

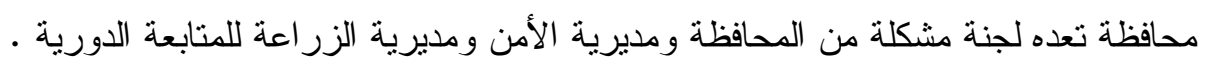

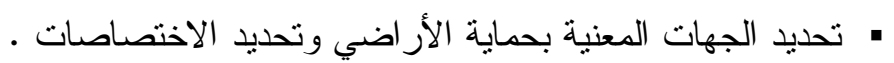

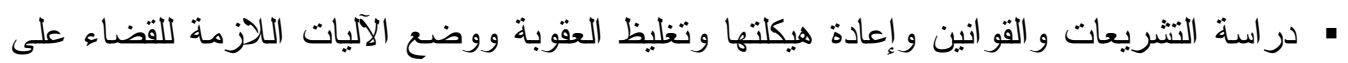
الظاهرة. • زيادة الحد الأدنى لغر امات البناء على الأراضي الزر اعية لتكون رادعه و أكثر فعاليه.

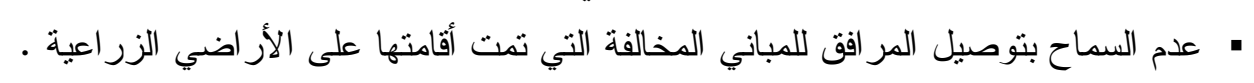

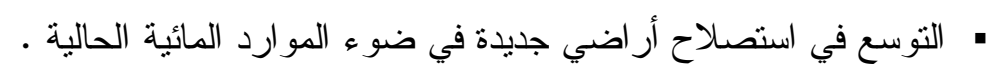

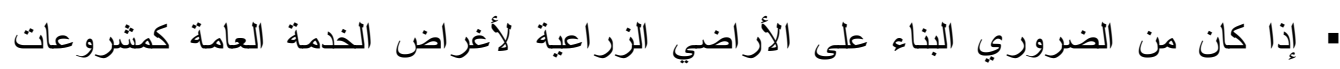

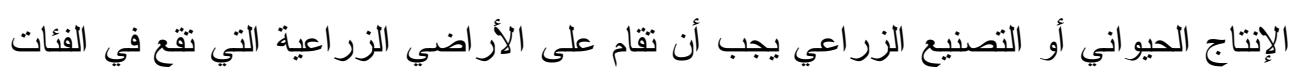
الخامسة و السادسة الني أثنرنا إليها سابقا. • التوسع في قرى الظهير الصحر اوي وإعادة النظر في سياسة التوطين ولاسيما في محافظات الوجه البحري و التي يتمركز بها مساحات التعدي على الأراضي الزر اعية بالبناء للحد من التعدي ولئي

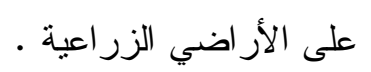
• الاستمر ار في صيانة وتحسين الأر اضي الزر اعية للحد من الفاقد النوعي في الأراضي الزر اعية.

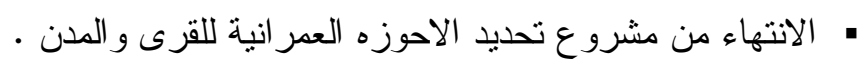

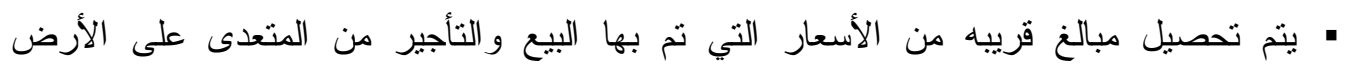
الزر اعية. • في ضوء القانون الجديد وتغليظ العقوبة بالسجن و الحبس وفداحة الغر امة المالية يتم تخصيص هذه المبالغ لاستصلاح أر اضي جديدة. • على الحكومة أن نوفر البنية الأساسية و الخدمات العامة (مو اصلات ــ أسواق ـ مخابز - مدارس

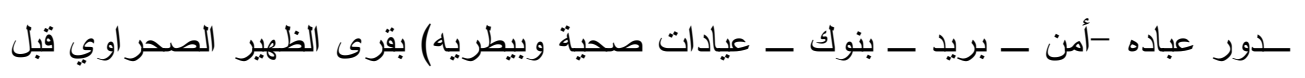

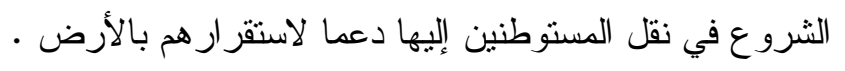




\section{المراجع}

1-أسامة عبد اللطيف عبد الصادق، الآثار الاقتصادية لظاهرة التصحر على الأراضي المصرية،

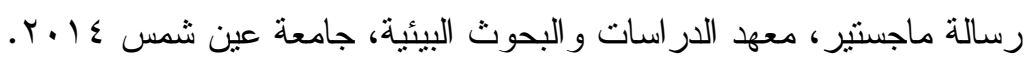

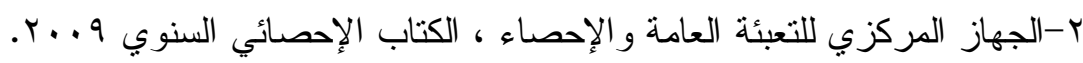

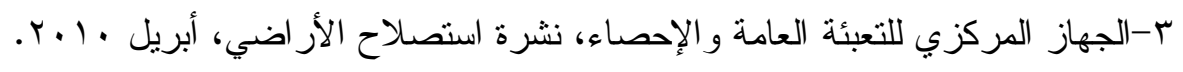

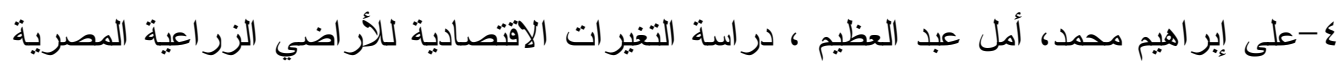

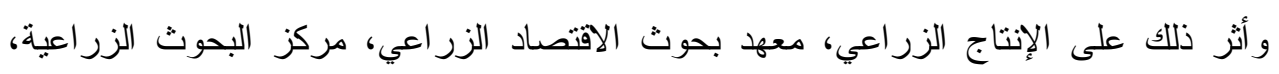

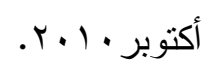

ه-على إبراهيم محمد ، الوضع الحالي والتصور المستقبلي للتعديات على الأراضي الزر اعبة المجلة

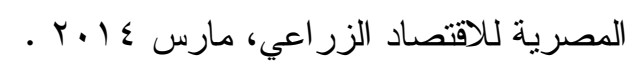

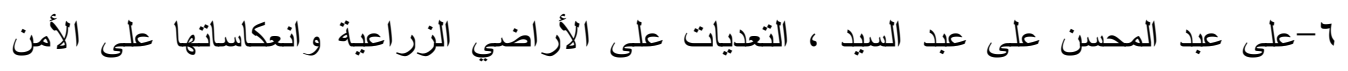

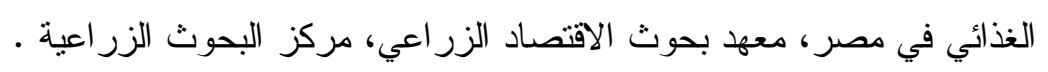

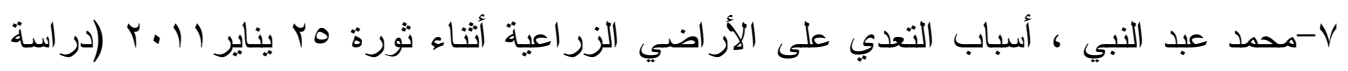

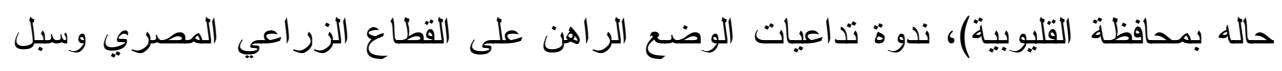

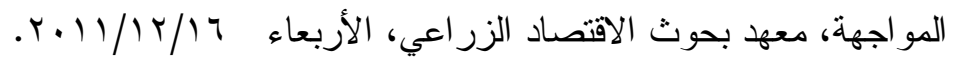

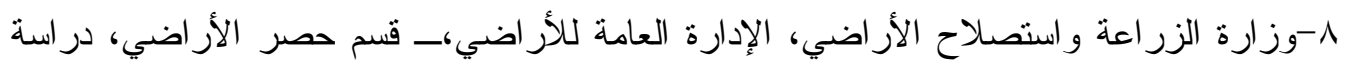

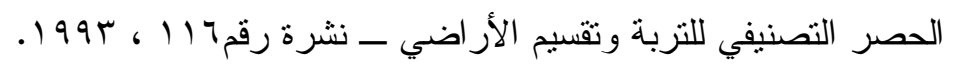

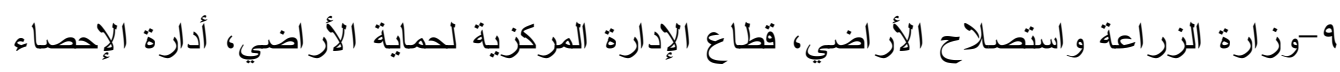

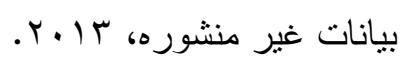

